\title{
Prevalencia de serotipos del virus de papiloma humano en mujeres de Ecuador
}

\author{
Prevalence of human papilloma virus serotypes in Ecuador women
}

Prevalência de serótipos do vírus do papiloma humano em mulheres do Ecuador

\author{
Jessica Roxana Yuxi Bustos \\ jessy25rox@hotmail.com \\ https://orcid.org/0000-0002-0786-1263
}

Universidad Católica de Cuenca, Ecuador

\author{
Santiago Homero Gallegos Vintimilla \\ sanhomeroo@hotmail.com \\ https://orcid.org/0000-0001-7697-2904 \\ Universidad Católica de Cuenca, Ecuador
}

Recibido 26 de febrero 2021 | Arbitrado y aceptado 19 de marzo 2021 | Publicado en 4 de mayo 2021

\begin{abstract}
RESUMEN
El Virus del Papiloma Humano constituye un problema de salud pública al presentar una prevalencia muy alta debido a que es una de las infecciones de transmisión sexual más frecuente a nivel mundial, está asociado a distintos tipos de cánceres sobre todo al cáncer cérvico uterino. Este cáncer es la segunda causa de muerte por enfermedades oncológicas en mujeres del Ecuador. Objetivo. Caracterizar la infección de Virus del Papiloma Humano a partir de la prevalencia de sus serotipos asociados a lesiones cervicales en mujeres del Ecuador durante el periodo enero 2010 hasta diciembre 2020. Metodología. Se realizó una revisión sistemática de tipo documental de acuerdo a la declaración PRISMA. Para lo cual se incluyeron artículos de investigación relacionados con la problemática. La búsqueda se realizó en bases de datos de gran impacto como PubMed, Scopus, ScieLO, Redalyc, Google Académico, Web of Science, Springer, Taylor \& Francis, Elsevier, MedLine; se encontraron 38 artículos de los cuales 10 fueron válidos para la investigación. Resultados. Los serotipos de Virus del Papiloma Humano más prevalentes del grupo de alto riesgo oncológico fueron el 16, 58, y 31; mientras que para los de bajo riesgo oncológico fueron los serotipos 61,81 y 6 . Conclusiones. No todas las regiones presentaron estudios de prevalencia de serotipos de VPH. Sin embargo, las regiones que si presentaron datos evidenciaron que el serotipo de alto riesgo oncológico más frecuente es el 16, mientras que el de bajo riesgo oncológico es el 61.
\end{abstract}

Palabras clave: Neoplasias del cuello uterino; Reacción en cadena de polimerasa; Riesgo oncológico; Virus de Papiloma Humano

\begin{abstract}
The Human Papilloma Virus constitutes a public health problem by presenting a very high prevalence due to the fact that it is one of the most frequent sexually transmitted infections worldwide, it is associated with different types of cancers especially cervical uterine cancer. This cancer is the second cause of death due to oncological diseases in women in Ecuador. Objective. The objective of this research was to characterize the infection of Human Papillomavirus from the prevalence of its serotypes associated with cervical lesions in women in Ecuador during the period January 2010 to December 2020. Methodology. A systematic documentary review was carried out according to the PRISMA statement. For this purpose, research articles related to the problem were included. The search was carried out in high impact databases such as PubMed, Scopus, ScieLO, Redalyc, Google Scholar, Web of Science, Springer, Taylor \& Francis, Elsevier, MedLine; thirty-eight articles were found of which 10 were valid for the research. Results. The most prevalent serotypes of Human Papillomavirus in the high oncologic risk group were 16, 58 and 31; while for the low oncologic risk group they were serotypes 61, 81 and 6. Conclusions. Not all regions presented studies of HPV serotype prevalence. However, the regions that did present data showed that the most frequent high oncologic risk serotype is 16, while the low oncologic risk serotype is 61 .
\end{abstract}

Key words: Uterine cervical neoplasms; Polymerase chain reaction; Oncologic risk; Human papillomavirus.

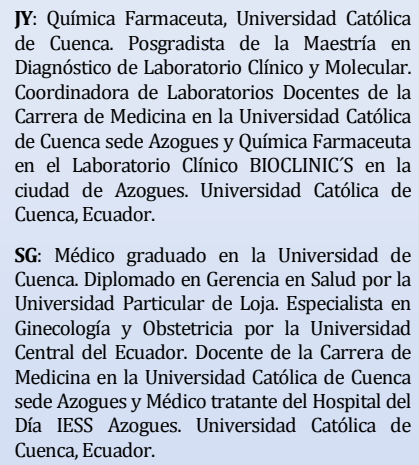
JY: Química Farmaceuta, Universidad Católica
de Cuenca. Posgradista de la Maestría en Diagnóstico de Laboratorio Clínico y Molecular. Diagnóstico de Laboratorio Clínico y Molecular. Coordinadora de Laboratorios Docentes de la Carrera de Medicina en la Universidad Católica
de Cuenca sede Azogues y Química Farmaceuta de Cuenca sede Azogues y Química Farmaceuta
en el Laboratorio Clínico BIOCLINIC'S en la ciudad de Azogues. Universidad Católica de Cuenca, Ecuador.

SG: Médico graduado en la Universidad de Cuenca. Diplomado en Gerencia en Salud por la Universidad Particular de Loja. Especialista en Ginecología y Obstetricia por la Universidad Central del Ecuador. Docente de la Carrera de Medicina en la Universidad Católica de Cuenca sede Azogues y Médico tratante del Hospital del Día IESS Azogues. Universidad Católica de Cuenca, Ecuador. 
JY: Química Farmaceuta, Universidad Católica de Cuenca. Posgradista de la Maestría en Diagnóstico de Laboratorio Clínico y Molecular. Coordinadora de Laboratorios Docentes de Coordina de de Carrera de Medicina en la Universidad Católica de Cuenca sede Azogues y Química Farmaceuta en el Laboratoro Chico BIOCLINIC'S en la ciudad de Azogues. Universidad Católica de Cuenca, Ecuador.

SG: Médico graduado en la Universidad de Cuenca. Diplomado en Gerencia en Salud por la Universidad Particula de Loja. Especilista Universidad Particular de Loja. Especialista en Ginecología y Obstetricia por la Universidad Central del Ecuador. Docente de la Carrera de Medicina en la Universidad Católica de Cuenca sede Azogues y Médico tratante del Hospital del Día IESS Azogues. Universidad Católica de Cuenca, Ecuador.

\section{RESUMO}

O Vírus do Papiloma Humano constitui um problema de saúde pública ao apresentar uma prevalência muito elevada porque é uma das infecções sexualmente transmissíveis mais frequentes em todo o mundo, está associado a diferentes tipos de cancros, especialmente o cancro do útero cervical. Este cancro é a segunda principal causa de morte por doenças oncológicas nas mulheres do Equador. Objectivo. 0 objectivo desta investigação era caracterizar a infecção pelo Papilomavírus Humano a partir da prevalência dos seus serótipos associados a lesões cervicais em mulheres no Equador durante o período de Janeiro de 2010 a Dezembro de 2020. Metodologia. Foi realizada uma revisão documental sistemática de acordo com a declaração do PRISMA. Foram incluídos artigos de investigação relacionados com o problema. A pesquisa foi realizada em bases de dados de alto impacto tais como PubMed, Scopus, ScieLO, Redalyc, Google Scholar, Web of Science, Springer, Taylor \& Francis, Elsevier, MedLine; foram encontrados 38 artigos dos quais 10 eram válidos para a pesquisa. Resultados: Os serotipos mais prevalentes do Papilomavírus Humano no grupo de alto risco oncológico foram 16, 58, e 31 ; enquanto para os de baixo risco oncológico foram os serotipos 61,81 , e 6 . Conclusões. Nem todas as regiões apresentaram estudos de prevalência do serotipo HPV. Contudo, as regiões que apresentaram dados mostraram que o serótipo de alto risco mais frequente é o 16, enquanto que o serótipo de baixo risco mais frequente é o 61.

Palavras-chave: Neoplasias cervicais; Reacção em cadeia da polimerase; Risco oncológico; Papilomavírus humano

\section{INTRODUCCIÓN}

$\mathrm{E}$ l inicio precoz de la actividad sexual en los seres humanos, la promiscuidad, la práctica de conductas sexuales inusuales, la falta de uso de métodos anticonceptivos de barrera, la deficiente educación sexual y otros factores incrementan el riesgo de padecer enfermedades de transmisión sexual que en algunos casos son mortales (1-3).

El Virus del Papiloma Humano (VPH) es una de las infecciones de trasmisión sexual con mayor incidencia a nivel mundial. Está asociada a patologías como cáncer de cuello uterino, cáncer de pene, cáncer oral, lesiones intraepiteliales anogenitales y condiloma genito-urinario, todas ellas causadas por serotipos de alto riesgo oncológico y enfermedades benignas como verrugas ano-genitales relacionadas con serotipos de bajo riesgo oncológico (2-5).

La infección por VPH suele ser auto limitada y aproximadamente el 90\% de las infecciones desaparecen en el transcurso de dos años. Si persisten por varios años dan lugar a lesiones precancerosas que termina en un cáncer invasor, este proceso puede tomar entre uno y 10 años o incluso hasta 20 años $(1,3,4,6)$.

Hasta el 2019 se habían identificado más de 220 serotipos de VPH, que de acuerdo a su potencial cancerígeno están divididos en serotipos de alto riesgo que tiene asociación con lesiones intraepiteliales y con el cáncer cérvico uterino, y los serotipos de bajo riesgo relacionados con lesiones benignas conocidas como condilomas $(4,7)$.

Se ha reportado que el $10 \%$ de mujeres en la población general tiene una infección genital por VPH y de ellas aproximadamente el $14 \%$ tiene una infección con serotipos de alto riesgo oncológico generalmente en mujeres entre 16 y 25 años (3).

En el año 2018 se notificaron 570.000 casos de cáncer de cuello uterino provocando 311.000 muertes en todo el mundo (8). 
La prevalencia global de VPH en cáncer cérvico uterino en poblaciones de África, América, Asia, Europa y Oceanía es del 84\% y el VPH más frecuente es el serotipo 16 con un porcentaje que va desde $52 \%$ en Asia a $58 \%$ en Europa. El segundo serotipo más frecuente es el 18 con un $13 \%$ en CentroaméricaSudamérica y un $22 \%$ en Norteamérica (2). Los otros serotipos virales más frecuentes en cáncer cérvico uterino son los mismos en todos los continentes y son: $31,33,35,45,52$ y 58. Los serotipos 52 y 58 se observan con mayor frecuencia en poblaciones de Asia $(2,9)$.

Según el censo poblacional del 2010 en el Ecuador existían 3'797.589 mujeres en edad fértil y se estima que mínimo el 50\% de los adultos sexualmente activos han presentado una infección por VPH en el transcurso de su vida. Alrededor del $1 \%$ de la población general padece de verrugas genitales y un $4 \%$ tiene lesiones intraepiteliales en cérvix. En el Ecuador el cáncer cérvico uterino es la segunda causa de muerte por enfermedades oncológicas en mujeres $(3,10)$.

Un gran porcentaje de los VPH no causan síntomas en la mayoría de personas, algunos provocan verrugas y otros aparecen como infecciones subclínicas que pueden dar lugar a cáncer tanto en hombres como en mujeres. El diagnóstico precoz del VPH es imprescindible para lograr un tratamiento oportuno y reducir el índice de mortalidad y morbilidad de las patologías asociadas a este virus. En la actualidad para el diagnóstico de cáncer cérvico uterino se utiliza la citología cérvico-vaginal o Papanicolaou, la colposcopia y la inspección visual con ácido acético. Dentro de las pruebas de laboratorio que se realizan están las técnicas de Biología Molecular como Reacción en Cadena de Polimerasa (PCR) en sus distintas variantes la cual permite la tipificación del virus (11-13). También existen pruebas serológicas, como ELISA, que detecta anticuerpos anti-VPH IgG el cual identifica el virus de manera temprana antes de que se produzca un carcinoma (2).

En la última década la alta prevalencia de VPH ha conducido al desarrollo de nuevas estrategias diagnósticas, preventivas $\mathrm{y}$ educativas. El diagnóstico molecular donde se identifica genéticamente al virus permite implementar medidas preventivas de manera específica para evitar o disminuir la progresión de éste en la población afectada. Una de estas medidas preventivas es la aplicación de las vacunas disponibles, las cuales son de tres tipos la bivalente 16,18, la tetravalente $6,11,16,18$ y la nonavalente $6,11,16,18,31,33,45,52$ y 58 que protegen contra determinados serotipos de VPH que no siempre son los mismos ya que estos dependen de la población y de las distintas áreas geográficas $(3,6,12,14,15)$.

En el estudio realizado por Zapata en la Universidad San Francisco de Quito "Genotipificación del virus de papiloma humano en mujeres que asisten a dos centros médicos privados entre 2013 y 2017" se determinó una prevalencia de serotipos de VPH de alto riesgo del $82.6 \%$ en mujeres de más de 40 años. Al igual que se identificaron 14 serotipos de alto riesgo de los cuales los más frecuentes fueron el 31 (19.5\%), 52 (18.6\%), 53 y 58 (16.1\%) (16). En razón de ello se considera como base el estudio antes mencionado para la realización de esta investigación que permita conocer de manera global la prevalencia de serotipos de VPH en las mujeres de Ecuador.

Aunque existen estudios sobre Prevalencia de serotipos de VPH realizados en distintas regiones del Ecuador no existe un estudio que reúna todos estos datos dispersos, en consecuencia, al no poder interpretarse de manera conjunta se puede generar errores en el manejo de este problema de salud en el país.

El objetivo de esta revisión es caracterizar la infección de VPH a partir de la 
prevalencia de sus serotipos asociado a lesiones cervicales en mujeres del Ecuador durante el periodo enero 2010 hasta diciembre 2020.

\section{MÉTODO}

$\mathrm{S}$ e realizó una revisión sistemática de tipo documental a partir de artículos de investigación originales tanto en inglés como en español publicados en bases de datos de alto impacto como: PubMed, Scopus, ScieLO, Redalyc, Google
Académico, Web of Science, Springer, Taylor \& Francis, Elsevier, MedLine, Biblioteca Virtual de la Universidad Católica de Cuenca.

Esta investigación se realizó de acuerdo a la declaración PRISMA (Preferred Reporting Items for Systematic reviews and Meta-Analyses) por lo que se basó en la siguiente pregunta de investigación (Ver Tabla 1): ¿Cuáles son los serotipos de VPH más prevalentes en las mujeres del Ecuador?

Tabla 1. Esquema de la pregunta PICO

\begin{tabular}{cccc}
\hline P & I & C & O \\
\hline Mujeres del Ecuador & Serotipos de VPH & $\begin{array}{c}\text { Alto riesgo, bajo } \\
\text { riesgo }\end{array}$ & Prevalencia \\
\hline
\end{tabular}

Para esta búsqueda se utilizaron palabras claves como: Virus del Papiloma Humano /

Human Papilloma Virus, VPH/ HPV, cáncer de cérvix / cervical cancer, Ecuador, Prevalencia / Prevalence, Serotipos / Serotypes, Genotipos / Genotypes. También se utilizaron operadores booleanos como "AND, OR, NOT", seleccionando únicamente los artículos publicados durante el periodo enero 2010 hasta diciembre 2020, además de esto se revisaron las referencias de los artículos seleccionados para identificar otras que no estaban en las bases de datos.

Para que un estudio sea elegible se tomó en cuenta el reporte de la prevalencia de serotipos de VPH.

Dentro de los criterios de inclusión que se aplicaron están: Artículos originales nacionales que indiquen la prevalencia de los serotipos de VPH; Investigaciones en las cuales se usan métodos moleculares como método de diagnóstico.

Estudios en donde la muestra analizada sea el cepillado cérvico-vaginal o biopsias. Como criterios de exclusión se consideraron: Artículos cuyos resultados no podían ser interpretados de manera correcta; Investigaciones que indicaban únicamente una prevalencia de VPH global y no especificaban la prevalencia de sus serotipos; Estudios en donde la muestra fueron pacientes hombres.

Una vez realizada la búsqueda en las bases de datos se encontraron un total de 38 artículos, solamente se eliminó un artículo duplicado. Los 37 artículos restantes fueron examinados a través de la lectura de sus títulos, resúmenes y aplicando los criterios de elegibilidad se eliminaron aquellos que correspondían a tesis de maestrías y especialidades. Se descartaron 13, resultando 24 artículos a los cuales se les realizó una lectura completa. Y aplicando los criterios de exclusión se descartaron 14 artículos debido a diferencias en el método de diagnóstico, resultados no interpretables y año de publicación. Finalmente se realizó la revisión sistemática con los 10 artículos. En la Figura 1 se resumen estos pasos. 


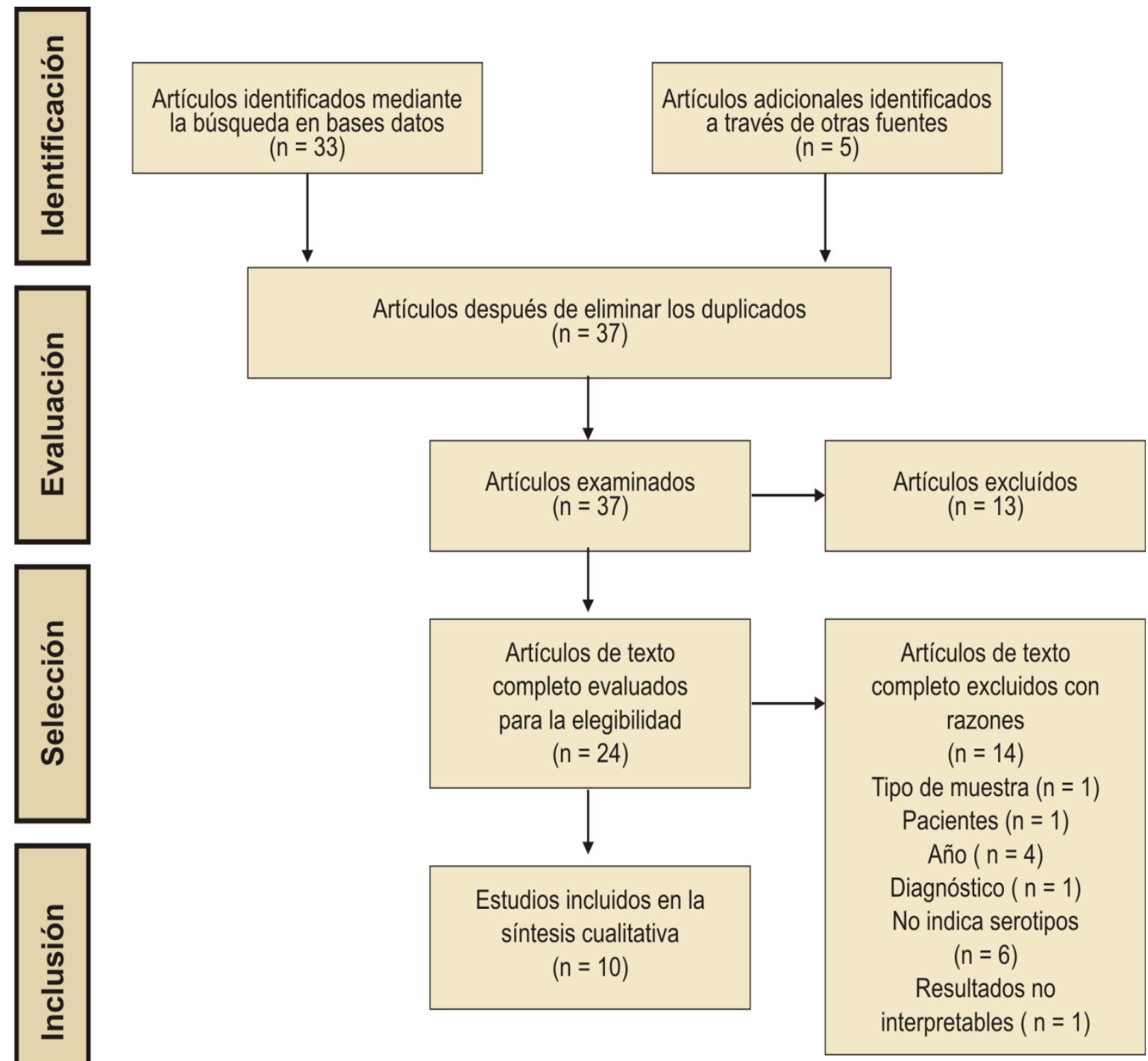

Figura 1. PRISMA. Diagrama de flujo.

Se seleccionaron 10 artículos finales, de los cuales se extrajeron los siguientes datos: ubicación del estudio, diseño del estudio, año de publicación, tipo de muestra, método de diagnóstico, edad de los participantes, frecuencias de los serotipos de VPH. Los resultados se resumen en la Tabla 2.

A partir de las prevalencias reportadas en cada investigación se calculó la prevalencia específica para cada serotipo de manera general y por regiones. 


\section{DESARROLLO Y DISCUSIÓN}

Tabla 2. Principales características de los estudios incluidos en esta investigación

\begin{tabular}{|c|c|c|c|c|c|c|c|c|c|}
\hline $\mathbf{N}^{\circ}$ & AÑO & AUTOR & & TÍTULO & $\begin{array}{l}\text { TIPO DE } \\
\text { ESTUDIO }\end{array}$ & LUGAR & POBLACIÓN & $\begin{array}{c}\text { MÉTODO DE } \\
\text { DIAGNÓSTICO }\end{array}$ & RESULTADOS \\
\hline 1 & 2014 & $\begin{array}{l}\text { Cárdenas } \\
\text { Cabrera } \\
\text { Campoverde } \\
\text { A. (17) }\end{array}$ & $\begin{array}{l}\mathrm{O}, \\
\mathrm{J},\end{array}$ & $\begin{array}{l}\text { Prevalencia de } \\
\text { genotipos del } \\
\text { papiloma virus en } \\
\text { mujeres de Cuenca }\end{array}$ & $\begin{array}{l}\text { Estudio } \\
\text { epidemiológico, } \\
\text { observacional de } \\
\text { tipo transversal. }\end{array}$ & $\begin{array}{l}\text { Parroquias } \\
\text { urbanas de } \\
\text { Cuenca }\end{array}$ & $\begin{array}{l}\text { Muestras } \\
\text { cervicales de } 500 \\
\text { mujeres de } 17 \text { a } \\
50 \text { añas en esta } \\
\text { reproductiva } \\
\text { designadas por } \\
\text { aleatorización. }\end{array}$ & $\begin{array}{l}\text { PCR } \\
\text { Papanicolaou }\end{array}$ & $\begin{array}{l}\text { La prevalencia de VPH positivo } \\
\text { fue del } 50.3 \% \text {. El } 35.9 \% \\
\text { serotipos de alto riesgo y el } \\
14.3 \% \text { de bajo riesgo. } \\
\text { Serotipo } 51: 10.3 \% \text {, serotipo } \\
16: 7.1 \text {, serotipo } 66: 5 \% \text {, } 5 \text {, } 5 \text {, serotipo } 43: \\
\text { serotipo } 42: 4.7 \% \text {, } 2.5 \% \\
\text { 3.5\%, serotipo } 6 \text { 11: }\end{array}$ \\
\hline 2 & 2015 & $\begin{array}{l}\text { Cabrera } \\
\text { Cárdenas } \\
\text { Campoverde } \\
\text { A, Ortiz J. ( } 14\end{array}$ & $\begin{array}{l}\text { J, } \\
0, \\
\text { ) }\end{array}$ & $\begin{array}{l}\text { Prevalencia de } \\
\text { genotipos del } \\
\text { papiloma virus } \\
\text { humano en } \\
\text { mujeres de la } \\
\text { provincia del } \\
\text { Azuay, Ecuador }\end{array}$ & $\begin{array}{l}\text { Estudio } \\
\text { epidemiológico, } \\
\text { observacional de } \\
\text { tipo transversal. }\end{array}$ & $\begin{array}{l}14 \text { cantones } \\
\text { de la } \\
\text { provincia del } \\
\text { Azuay }\end{array}$ & $\begin{array}{l}\text { Muestra cérvico- } \\
\text { uterina de } 500 \\
\text { mujeres de } 17 \text { a } \\
50 \text { años con vida } \\
\text { sexual activa } \\
\text { obtenida de } \\
\text { manera } \\
\text { aleatoria, } \\
\text { estratificada y } \\
\text { ponderada }\end{array}$ & $\begin{array}{l}\text { Papanicolaou } \\
\text { PCR en tiempo } \\
\text { real multiplex }\end{array}$ & $\begin{array}{l}\text { Obtuvieron un } 25.6 \% \text { de VPH } \\
\text { positivo. Los serotipos de alto } \\
\text { riesgo se presentaron en un } \\
20.8 \% \text { y los de bajo riesgo en } \\
\text { un } 4.8 \% \text {. El serotipo } 6 \text { con } 1 \% \text {, } \\
\text { no se presentó el serotipo } 11 . \\
\text { Los serotipos de bajo riesgo } \\
\text { más prevalentes fueron el } 42 \text { y } \\
54 \text { con el } 2 \% \text {. Los serotipos de } \\
\text { alto riesgo como el } 16 \text { se } \\
\text { encontró en un } 2.2 \% \text { y el } 18 \text { el } \\
0.6 \% \text { siendo los más } \\
\text { prevalentes el } 66 \text { con } 3,2 \% \text { y el } \\
68 \text { con un } 2.8 \%\end{array}$ \\
\hline 3 & 2016 & $\begin{array}{l}\text { García } \\
\text { García } \\
\text { Burgos } \\
\text { Almeida } \\
\text { Ruiz J. (18) }\end{array}$ & $\begin{array}{l}\text { G, } \\
\text { L, } \\
\text { R, } \\
\text { F, }\end{array}$ & $\begin{array}{l}\text { Genotypes } \\
\text { distribution of } \\
\text { human } \\
\text { papillomavirus in } \\
\text { cervical samples of } \\
\text { Ecuadorian women }\end{array}$ & $\begin{array}{l}\text { Estudio } \\
\text { transversal }\end{array}$ & $\begin{array}{l}\text { SOLCA } \\
\text { Guayaquil }\end{array}$ & $\begin{array}{l}\text { Muestras } \\
\text { cervicales de } \\
1581 \text { mujeres de } \\
20 \text { a } 70 \text { años }\end{array}$ & PCR convencional & $\begin{array}{l}689 \text { muestras ( } 43.58 \%) \text { fueron } \\
\text { positivas para VPH. El serotipo } \\
16 \text { tuvo una prevalencia del } \\
5.50 \% \text {, el } 33: 4.55 \%, 66: 2.59 \% \text {, } \\
\text { el } 11 \text { : } 3.80 \% \text {. } 85 \text { casos } \\
\text { presentaron infección múltiple } \\
\text { con } 2 \text { serotipos, } 11 \text { con } 3 \\
\text { serotipos y } 7 \text { con } 4 \text { serotipos. }\end{array}$ \\
\hline
\end{tabular}




\begin{tabular}{|c|c|c|c|c|c|c|c|c|}
\hline $\mathbf{N}^{\circ}$ & AÑO & AUTOR & TÍTULO & $\begin{array}{l}\text { TIPO DE } \\
\text { ESTUDIO }\end{array}$ & LUGAR & POBLACIÓN & $\begin{array}{c}\text { MÉTODO DE } \\
\text { DIAGNÓSTICO }\end{array}$ & RESULTADOS \\
\hline 4 & 2016 & $\begin{array}{l}\text { Mejía L, } \\
\text { Muñoz D, } \\
\text { Trueba G, } \\
\text { Tinoco L, } \\
\text { Zapata S. (19) }\end{array}$ & $\begin{array}{l}\text { Prevalence of } \\
\text { Human } \\
\text { Papillomavirus } \\
\text { Types in Cervical } \\
\text { Cancerous and } \\
\text { Precancerous } \\
\text { Lesions of } \\
\text { Ecuadorian } \\
\text { Women }\end{array}$ & & SOLCA Quito & $\begin{array}{l}164 \text { biopsias } \\
\text { cervicales } \\
\text { precancerosas o } \\
\text { cancerosas de } \\
\text { mujeres de } 19 \text { a } \\
77 \text { años }\end{array}$ & $\begin{array}{l}\text { PCR más } \\
\text { hibridación }\end{array}$ & $\begin{array}{l}\text { Se detectaron } 19 \text { de los } 21 \\
\text { serotipos los más frecuentes } \\
\text { fueron el 16: } 40.6 \% \text {, el } 58 \text { : } \\
25 \% \text {, el } 18: 2.8 \% \text {. }\end{array}$ \\
\hline 5 & 2017 & $\begin{array}{l}\text { Campoverde } \\
\text { A, Arcentales } \\
\text { M, Caguana J. } \\
\text { (20) }\end{array}$ & $\begin{array}{l}\text { Caracterización de } \\
\text { los genotipos } \\
\text { frecuentes del } \\
\text { virus del papiloma } \\
\text { humano en } \\
\text { mujeres atendidas } \\
\text { en los hospitales } \\
\text { Monte Sinaí y del } \\
\text { Seguro Social } \\
\text { Cuenca-Ecuador. } \\
2008-2014\end{array}$ & $\begin{array}{l}\text { Estudio } \\
\text { epidemiológico, } \\
\text { observacional de } \\
\text { tipo transversal y } \\
\text { correlacional. }\end{array}$ & Cuenca & $\begin{array}{l}500 \text { mujeres de } \\
15 \text { a } 76 \text { años con } \\
\text { vida sexual } \\
\text { activa }\end{array}$ & $\begin{array}{l}\text { PCR multiplex en } \\
\text { tiempo real }\end{array}$ & $\begin{array}{l}\text { De la totalidad de la población } \\
\text { estudiada el } 78.4 \% \text { resultaron } \\
\text { positivas para VPH, siendo el } \\
\text { serotipo más frecuente el } 16 \\
\text { con un } 26.2 \% \text { seguido del } 31 \text { : } \\
11.5 \%, 51: 10.2 \%, 18 \text { con un } \\
4.5 \%\end{array}$ \\
\hline 6 & 2017 & $\begin{array}{l}\text { Bedoya C, } \\
\text { Medina L, } \\
\text { Espinosa M, } \\
\text { Sánchez M, } \\
\text { Parrales J, } \\
\text { Molina D, } \\
\text { Ibarra M, } \\
\text { Quimis M, } \\
\text { España K, } \\
\text { Párraga K, } \\
\text { Cajas N, } \\
\text { Orlando S, } \\
\text { Robalino J, } \\
\text { Chedraui P, } \\
\text { Escobar S, Loja }\end{array}$ & $\begin{array}{l}\text { Molecular } \\
\text { epidemiology and } \\
\text { phylogenetic } \\
\text { analysis of human } \\
\text { papillomavirus } \\
\text { infection in women } \\
\text { with cervical } \\
\text { lesions and cancer } \\
\text { from the coastal } \\
\text { region of Ecuador }\end{array}$ & & $\begin{array}{l}\text { SOLCA de } \\
\text { Esmeraldas, } \\
\text { Manabí, Los } \\
\text { Ríos, Santa } \\
\text { Elena, Guayas } \\
\text { y El Oro }\end{array}$ & $\begin{array}{l}166 \text { muestras } \\
\text { cervicales y } \\
\text { biopsias frescas } \\
\text { de mujeres } \\
\text { diagnosticadas } \\
\text { con lesiones } \\
\text { cervicales y } \\
\text { cáncer }\end{array}$ & $\begin{array}{l}\text { PCR con } \\
\text { electroforesis }\end{array}$ & $\begin{array}{l}\text { Del total de las muestras } 113 \\
(68.1 \%) \text { fueron positivas para } \\
\text { VPH. Los serotipos más } \\
\text { frecuentes fueron el } 16: 38.9 \% \text {, } \\
58 \text { con el } 19.5 \% \text { y el } 18 \text { es el } \\
\text { cuarto serotipo más común }\end{array}$ \\
\hline
\end{tabular}




\begin{tabular}{|c|c|c|c|c|c|c|c|c|}
\hline $\mathbf{N}^{\circ}$ & AÑo & AUTOR & TÍTULO & $\begin{array}{l}\text { TIPO DE } \\
\text { ESTUDIO }\end{array}$ & LUGAR & POBLACIÓN & $\begin{array}{c}\text { MÉTODO DE } \\
\text { DIAGNÓSTICO }\end{array}$ & RESULTADOS \\
\hline & & $\begin{array}{l}\text { R, Ramirez C, } \\
\text { Espinoza } \\
\text { Jasson, } \\
\text { Sánchez S, } \\
\text { Limia C, } \\
\text { Alemán Y, Soto } \\
\text { Y, Kouri V, } \\
\text { Culasso A, } \\
\text { Badano I. (21) }\end{array}$ & & & & & & \\
\hline 7 & 2017 & $\begin{array}{l}\text { Dalgo P, Loján } \\
\text { C, Córdova A, } \\
\text { Acurio K, } \\
\text { Arévalo A, } \\
\text { Bobokova J. } \\
(22)\end{array}$ & $\begin{array}{l}\text { Prevalence of High- } \\
\text { Risk Genotypes of } \\
\text { Human } \\
\text { Papillomavirus: } \\
\text { Women Diagnosed } \\
\text { with Premalignant } \\
\text { and Malignant Pap } \\
\text { Smear Test in } \\
\text { Southern Ecuador }\end{array}$ & $\begin{array}{l}\text { Estudio } \\
\text { observacional, de } \\
\text { tipo transversal y } \\
\text { prospectivo. }\end{array}$ & $\begin{array}{l}\text { SOLCA y } \\
\text { APROFE Loja, } \\
\text { Zamora y El } \\
\text { Oro }\end{array}$ & $\begin{array}{l}\text { Muestras } \\
\text { cervicales de } 431 \\
\text { mujeres entre } 17 \\
\text { a } 84 \text { años }\end{array}$ & $\begin{array}{l}\text { PCR en tiempo } \\
\text { real }\end{array}$ & $\begin{array}{l}278 \text { muestras }(64.5 \%) \text { fueron } \\
\text { positivas para VPH. Los } \\
\text { serotipos } 16 \text { y } 18 \text { fueron los } \\
\text { más prevalentes con un } 53.2 \% \\
\text { y el } 38.8 \% \text { respectivamente }\end{array}$ \\
\hline 8 & 2019 & $\begin{array}{l}\text { Tigre P, } \\
\text { Salazar Z, } \\
\text { Espinosa L, } \\
\text { Aspiazu K, } \\
\text { Espinosa M, } \\
\text { Cárdena F. } \\
(23)\end{array}$ & $\begin{array}{l}\text { Human Papilloma } \\
\text { Virus genotypes in } \\
\text { Type III cervical } \\
\text { intraepithelial } \\
\text { neoplasia. Cuenca- } \\
\text { Ecuador, 2013- } \\
2017\end{array}$ & $\begin{array}{l}\text { Estudio analítico } \\
\text { no experimental, } \\
\text { transversal y } \\
\text { retrospectivo. }\end{array}$ & $\begin{array}{l}\text { SOLCA } \\
\text { Cuenca }\end{array}$ & $\begin{array}{l}195 \text { mujeres con } \\
\text { diagnóstico de } \\
\text { neoplasia } \\
\text { intraepitelial III } \\
\text { entre } 20 \text { a } 60 \\
\text { años }\end{array}$ & $\begin{array}{l}\text { PCR más Captura } \\
\text { híbrida }\end{array}$ & $\begin{array}{l}155 \text { mujeres resultaron } \\
\text { positivas para infección por } \\
\text { VPH. El serotipo } 16 \text { fue el más } \\
\text { común }(32.9 \%) \text { seguido del } 31 \\
(11.6 \%) \text {, el } 58 \text { con el } 7.7 \% \text {, el } \\
33 \text { y } 52 \text { con el } 3.3 \% \text { y otros } \\
\text { serotipos con menos del } 2 \% \text {. }\end{array}$ \\
\hline 9 & 2019 & $\begin{array}{l}\text { García G, } \\
\text { Mendoza M, } \\
\text { Burgos R, } \\
\text { Ollague K, } \\
\text { Vargas C, Ruiz } \\
\text { J. (24) }\end{array}$ & $\begin{array}{l}\text { Frequency and } \\
\text { distribution of HPV } \\
\text { genotypes in } 800 \\
\text { genital samples of } \\
\text { Ecuadorian men } \\
\text { and women from } \\
\text { the city of } \\
\text { Guayaquil }\end{array}$ & & $\begin{array}{l}\text { SOLCA } \\
\text { Guayaquil }\end{array}$ & $\begin{array}{l}800 \text { cepillados } \\
\text { genitales } 400 \\
\text { hombres y } 400 \\
\text { mujeres entre } 10 \\
\text { a } 70 \text { años }\end{array}$ & $\begin{array}{l}\text { PCR convencional } \\
\text { más hibridación } \\
\text { con sondas } \\
\text { especificas }\end{array}$ & $\begin{array}{l}158 \text { muestras de mujeres } \\
(39.5 \%) \text { fueron positivas para } \\
\text { VPH. Los serotipos más } \\
\text { frecuentes en mujeres fueron } \\
39: 17.09 \% \text {, } 16: 13.92 \% \text {, } 6: \\
13.29 \% \text { y el } 58: 10.76 \%\end{array}$ \\
\hline
\end{tabular}




\begin{tabular}{|c|c|c|c|c|c|c|c|c|}
\hline $\mathbf{N}^{\circ}$ & AÑO & AUTOR & TÍTULO & $\begin{array}{c}\text { TIPO DE } \\
\text { ESTUDIO }\end{array}$ & LUGAR & POBLACIÓN & $\begin{array}{c}\text { MÉTODO DE } \\
\text { DIAGNÓSTICO }\end{array}$ & RESULTADOS \\
\hline 10 & 2020 & $\begin{array}{l}\text { Carrión J, Soto } \\
\text { Y, Pupo M. } \\
(25)\end{array}$ & $\begin{array}{l}\text { Infección por virus } \\
\text { del papiloma } \\
\text { humano en } \\
\text { mujeres del Cantón } \\
\text { Cañar, Ecuador }\end{array}$ & $\begin{array}{l}\text { Estudio } \\
\text { descriptivo de } \\
\text { corte transversal. }\end{array}$ & $\begin{array}{l}\text { Cañar- } \\
\text { Ecuador }\end{array}$ & $\begin{array}{l}\text { Muestras } \\
\text { cervicouterinas } \\
\text { de } 100 \text { mujeres } \\
\text { entre } 15 \text { y } 55 \\
\text { años } \\
\text { sexualmente } \\
\text { activas }\end{array}$ & $\begin{array}{l}\text { Papanicolaou } \\
\text { PCR }\end{array}$ & $\begin{array}{l}\text { Se identificaron } 26 \text { serotipos } \\
\text { diferentes predominado los de } \\
\text { alto riego oncogénico. El } \\
\text { serotipo } 31 \text { fue el más } \\
\text { frecuente }(56.9 \%) \text { seguido del } \\
31: 56.9 \% \text { y del } 58: 43.1 \% \text {. los } \\
\text { serotipos de bajo riesgo como } \\
\text { el } 6 \text { y } 11 \text { se encontraron en un } \\
2 \% \text {. }\end{array}$ \\
\hline
\end{tabular}

En esta investigación se incluyeron diez artículos, cuyas poblaciones de estudio estaban constituidas por mujeres con un rango de edad desde los 15 hasta los 74 años, que tenían actividad sexual y presentaban o no algún tipo de Lesión Intraepitelial (LIE), la muestra utilizada era proveniente del cepillado cérvico-uterino. En la mayoría de las investigaciones el ADN del VPH de las muestras fue analizado a través de distintas pruebas moleculares, como captura de híbridos y PCR con diferentes cebadores. 
Tabla 3. Prevalencia de los serotipos del Virus del Papiloma Humano en las mujeres del Ecuador.

\begin{tabular}{|c|c|c|c|c|c|c|c|c|c|c|c|c|c|c|c|c|c|c|c|c|c|c|}
\hline \multirow[b]{2}{*}{ SEROTIPOS DE VPH } & \multicolumn{2}{|c|}{$\begin{array}{c}\text { Cárdenas } \\
0,2014 \\
1\end{array}$} & \multicolumn{2}{|c|}{$\begin{array}{c}\text { Cabrera } \\
\text { J, } 2015 \\
2\end{array}$} & \multicolumn{2}{|c|}{$\begin{array}{c}\text { García G, } \\
2016 \\
3\end{array}$} & \multicolumn{2}{|c|}{$\begin{array}{c}\text { Mejía L, } \\
2016 \\
4\end{array}$} & \multicolumn{2}{|c|}{$\begin{array}{c}\text { Campoverde } \\
\text { A, } 2017 \\
5\end{array}$} & \multicolumn{2}{|c|}{$\begin{array}{c}\text { Bedoya C, } \\
2017 \\
6\end{array}$} & \multicolumn{2}{|c|}{$\begin{array}{c}\text { Dalgo P, } \\
2017 \\
7\end{array}$} & \multicolumn{2}{|c|}{$\begin{array}{c}\text { Tigre } P, \\
2019 \\
8\end{array}$} & \multicolumn{2}{|c|}{$\begin{array}{c}\text { García G, } \\
2019 \\
9\end{array}$} & \multicolumn{2}{|c|}{$\begin{array}{c}\text { Carrión } \\
\text { J, } 2020 \\
10\end{array}$} & \multicolumn{2}{|c|}{ TOTAL } \\
\hline & n & $\%$ & $\mathrm{n}$ & $\%$ & $\mathrm{n}$ & $\%$ & $\mathrm{n}$ & $\%$ & $\mathbf{n}$ & $\%$ & $n$ & $\%$ & $\mathrm{n}$ & $\%$ & $\mathrm{n}$ & $\%$ & $\mathrm{n}$ & $\%$ & $\mathrm{n}$ & $\%$ & $\mathrm{n}$ & $\%$ \\
\hline 16 & & 7,1 & & 2,2 & 87 & 5,5 & 59 & 41,8 & 64 & 26,2 & 39 & 23,5 & 52 & 47,3 & 51 & 32,9 & & 13,92 & & 7,8 & & 20,8 \\
\hline 18 & & 0,9 & & 0,6 & 50 & 3,16 & 4 & 2,8 & 11 & 4,5 & 4 & 2,4 & 17 & 15,5 & 1 & 0,6 & & 3,16 & & 5,9 & & 4,0 \\
\hline 31 & & 0,9 & & 1,8 & & 1,2 & 10 & 7,1 & 28 & 11,5 & 6 & 3,6 & 3 & 2,7 & 18 & 11,6 & & 9,49 & & 56,9 & & 10,7 \\
\hline 33 & & & & 1,4 & & 4,55 & 4 & 2,8 & 23 & 9,4 & 2 & 1,2 & 1 & 0,9 & 5 & 3,3 & & 3,16 & & 2 & & 3,2 \\
\hline 34 & & & & & & & & & & & & & & & & & & 1,9 & & & & 1,9 \\
\hline 35 & & 1,9 & & 0,6 & & 0,44 & 4 & 2,8 & 8 & 3,3 & 2 & 1,2 & 0 & 0 & 2 & 1,2 & & 1,27 & & 13,7 & & 2,6 \\
\hline 52 & & 3,6 & & 1 & & 1,27 & 17 & 12,1 & 17 & 7 & 4 & 2,4 & 1 & 0,9 & 5 & 3,3 & & 8,86 & & 3,9 & & 4,4 \\
\hline 53 & & & & 1,2 & & 0,82 & 1 & 0,7 & & & 7 & 4,2 & & & 1 & 0,6 & & 6,33 & & 5,9 & & 2,8 \\
\hline 56 & & 0,6 & & 1 & & 2,15 & 1 & 0,7 & 14 & 5,7 & 2 & 1,2 & 5 & 4,6 & 1 & 0,6 & & 5,7 & & 2 & & 2,4 \\
\hline 58 & & 1,3 & & 1,4 & & 2,02 & 43 & 30,5 & 14 & 5,7 & 18 & 10,8 & 11 & 10 & 12 & 7,7 & & 10,76 & & 43,1 & & 12,3 \\
\hline 59 & & 0,7 & & 2 & & 0,82 & 3 & 2,1 & 4 & 1,6 & & & 9 & 8,2 & 1 & 0,6 & & 2,53 & & 23,5 & & 4,7 \\
\hline 66 & & 5 & & 3,2 & & 2,59 & 11 & 7,8 & 17 & 7 & 1 & 0,6 & & & 2 & 1,2 & & 8,86 & & 29,4 & & 6,6 \\
\hline
\end{tabular}




\begin{tabular}{|c|c|c|c|c|c|c|c|c|c|c|c|c|c|c|c|}
\hline & $\begin{array}{c}\text { Cárdenas } \\
0,2014 \\
1\end{array}$ & $\begin{array}{c}\text { Cabrera } \\
\text { J, } 2015 \\
2\end{array}$ & $\begin{array}{c}\text { García G, } \\
2016 \\
3\end{array}$ & \multicolumn{2}{|c|}{$\begin{array}{c}\text { Mejía L, } \\
2016 \\
4\end{array}$} & \multicolumn{2}{|c|}{$\begin{array}{c}\text { Campoverde } \\
\text { A, } 2017 \\
5\end{array}$} & \multicolumn{2}{|c|}{$\begin{array}{c}\text { Bedoya C, } \\
2017 \\
6\end{array}$} & \multirow[t]{2}{*}{$\begin{array}{c}\text { Dalgo P, } \\
2017 \\
7\end{array}$} & \multicolumn{2}{|c|}{$\begin{array}{c}\text { Tigre P, } \\
2019 \\
8\end{array}$} & \multirow{2}{*}{$\begin{array}{c}\text { García G, } \\
2019 \\
9 \\
0,63\end{array}$} & \multirow[t]{2}{*}{$\begin{array}{c}\text { Carrión } \\
\text { J, } 2020 \\
10\end{array}$} & \multirow{2}{*}{$\begin{array}{r}\text { TOTAL } \\
0,5\end{array}$} \\
\hline 67 & & & 0,38 & & & & & & & & & & & & \\
\hline 68 & 1,3 & 2,8 & 0,19 & 5 & 3,5 & 4 & 1,6 & & & & & & 5,06 & 7,8 & 3,2 \\
\hline 73 & & 0,4 & 0,63 & & & & & 1 & 0,6 & & & & 1,9 & & 0,9 \\
\hline 82 & & 0,2 & 0,38 & & & & & & & & & & 1,9 & 3,9 & 1,6 \\
\hline 85 & & & & & & & & & & & & & & 2 & 2,0 \\
\hline \multicolumn{16}{|l|}{ BAJO RIESGO } \\
\hline 6 & 2,5 & 1 & 2,09 & 13 & 9,2 & & & 3 & 1,8 & & & & 13,29 & 2 & 4,6 \\
\hline 11 & 2,5 & 0 & 3,8 & 13 & 9,2 & & & 1 & 0,6 & & & & 5,06 & 2 & 3,3 \\
\hline 32 & & & & & & & & 1 & 0,6 & & & & & & 0,6 \\
\hline 40 & & 0,4 & 0,57 & & & & & & & & & & 1,27 & & 0,7 \\
\hline 42 & 4,7 & 2 & 0,76 & 1 & 0,7 & & & 1 & 0,6 & & & & 3,16 & & 2,0 \\
\hline 43 & 3,5 & 0,4 & & 10 & 7,1 & & & & & & & & 1,27 & & 3,1 \\
\hline 44 & 1,2 & 0,6 & & 1 & 0,7 & & & & & & & & 1,9 & & 1,1 \\
\hline 49 & & & & & & & & & & & 3 & 1,9 & & & 1,9 \\
\hline 54 & & 2 & 2,09 & & & & & & & & & & 5,7 & 2 & 2,9 \\
\hline 55 & & & 0,82 & & & & & & & & & & 1,9 & & 1,4 \\
\hline 57 & & & & & & & & & & & & & 0 & & 0,0 \\
\hline 61 & & 1,6 & 0,82 & & & & & 1 & 0,6 & & & & 5,06 & 37,3 & 9,1 \\
\hline
\end{tabular}




\begin{tabular}{|c|c|c|c|c|c|c|c|c|c|c|c|c|c|c|}
\hline & $\begin{array}{c}\text { Cárdenas } \\
0,2014 \\
1\end{array}$ & $\begin{array}{c}\text { Cabrera } \\
\text { J, } 2015 \\
2\end{array}$ & $\begin{array}{c}\text { García G, } \\
2016 \\
3\end{array}$ & \multicolumn{2}{|c|}{$\begin{array}{c}\text { Mejía L, } \\
2016 \\
4\end{array}$} & $\begin{array}{c}\text { Campoverde } \\
\text { A, } 2017 \\
5\end{array}$ & \multicolumn{2}{|c|}{$\begin{array}{c}\text { Bedoya C, } \\
2017 \\
6\end{array}$} & $\begin{array}{c}\text { Dalgo P, } \\
2017 \\
7\end{array}$ & \multicolumn{2}{|c|}{$\begin{array}{c}\text { Tigre } P, \\
2019 \\
8\end{array}$} & $\begin{array}{c}\text { García G, } \\
2019 \\
9\end{array}$ & $\begin{array}{c}\text { Carrión } \\
\text { J, } 2020 \\
10\end{array}$ & TOTAL \\
\hline 62 & & & 1,45 & & & & 1 & 0,6 & & & & & 3,9 & 2,0 \\
\hline 64 & & & 0,19 & & & & & & & & & & & 0,19 \\
\hline 69 & & 0,2 & 0,44 & & & & & & & & & 0,63 & & 0,4 \\
\hline 70 & & 0,4 & 1,45 & & & & 2 & 1,2 & & & & 2,53 & 9,8 & 3,1 \\
\hline 71 & & & 0,82 & & & & 1 & 0,6 & & 3 & 1,9 & 3,16 & 2 & 1,7 \\
\hline 72 & & & 0,7 & & & & 1 & 0,6 & & & & 0 & 5,9 & 1,8 \\
\hline 81 & & & 0,63 & 0 & 0 & & & & & & & 9,49 & 9,8 & 5,0 \\
\hline 83 & & & 0,7 & & & & & & & & & 0,63 & 7,8 & 3,0 \\
\hline 84 & & & 1,2 & & & & & & & & & 0 & 5,9 & 2,4 \\
\hline СР6108 & & & 1,52 & & & & & & & & & & & 1,52 \\
\hline IS39 & & & 0,06 & & & & & & & & & & & 0,06 \\
\hline OTROS & & & & & & & & & & 15 & 9,6 & & & 9,6 \\
\hline
\end{tabular}

La prevalencia de los serotipos de VPH de alto riesgo oncogénico en orden descendente fue: $16,58,31,66,51,59,52,39,18,33,68,53,35,56,85,34,82,45,73,26,67$.

La prevalencia de los serotipos de VPH de bajo riesgo oncogénico en orden descendente fue: $61,81,6,11,43,70,83,54,84,42,62,49,72,71, \mathrm{CP} 6108,55,44,40,32,69,64$, IS39, 57. Existe una prevalencia del $9.6 \%$ de serotipos no especificados. 
Tabla 4. Prevalencia de los serotipos de VPH en las mujeres del Ecuador por regiones.

\begin{tabular}{|c|c|c|c|c|c|c|c|c|c|c|c|c|c|c|c|c|c|c|c|c|c|c|c|c|c|c|}
\hline \multirow[b]{4}{*}{ SEROTIPOS DE VPH } & \multicolumn{8}{|c|}{ REGIÓN COSTA } & \multicolumn{14}{|c|}{ REGIÓN SIERRA } & \multicolumn{4}{|c|}{ OTROS } \\
\hline & \multirow{2}{*}{\multicolumn{2}{|c|}{$\begin{array}{c}\text { García G, } \\
2016 \\
3\end{array}$}} & \multirow{2}{*}{\multicolumn{2}{|c|}{$\begin{array}{c}\text { Bedoya } \\
\text { C, } 2017 \\
6\end{array}$}} & \multirow{2}{*}{\multicolumn{2}{|c|}{$\begin{array}{c}\text { García G, } \\
2019 \\
9\end{array}$}} & \multirow{2}{*}{\multicolumn{2}{|c|}{ TOTAL }} & \multirow{2}{*}{\multicolumn{2}{|c|}{$\begin{array}{c}\text { Cárdenas } \\
0,2014 \\
1\end{array}$}} & \multirow{2}{*}{\multicolumn{2}{|c|}{$\begin{array}{c}\text { Cabrera } \\
\text { J, } 2015 \\
2\end{array}$}} & \multirow{2}{*}{\multicolumn{2}{|c|}{$\begin{array}{c}\text { Mejía L, } \\
2016 \\
4\end{array}$}} & \multirow{2}{*}{\multicolumn{2}{|c|}{$\begin{array}{c}\text { Campoverde } \\
\text { A, } 2017 \\
5\end{array}$}} & \multirow{2}{*}{\multicolumn{2}{|c|}{$\begin{array}{c}\text { Tigre P, } \\
2019 \\
8\end{array}$}} & \multirow{2}{*}{\multicolumn{2}{|c|}{$\begin{array}{c}\text { Carrión } \\
\text { J, } 2020 \\
10\end{array}$}} & \multirow{2}{*}{\multicolumn{4}{|c|}{$\begin{array}{c}\text { Dalgo P, } \\
2017 \\
7\end{array}$}} & \multirow{2}{*}{\multicolumn{2}{|c|}{ TOTAL }} \\
\hline & & & & & & & & & & & & & & & & & & & & & & & & & & \\
\hline & $\mathbf{n}$ & $\%$ & $\mathbf{n}$ & $\%$ & $\mathbf{n}$ & $\%$ & $\mathbf{n}$ & $\%$ & $\mathbf{n}$ & $\%$ & $\mathbf{n}$ & $\%$ & $\mathbf{n}$ & $\%$ & $n$ & $\%$ & $\mathbf{n}$ & $\%$ & $\mathbf{n}$ & $\%$ & n & $\%$ & $\mathrm{n}$ & $\%$ & $\mathrm{n}$ & $\%$ \\
\hline \multicolumn{27}{|l|}{ ALTO RIESGO } \\
\hline 16 & 87 & 5,5 & 39 & 23,5 & & 13,92 & & 14,3 & & 7,1 & & 2,2 & 59 & 41,8 & 64 & 26,2 & 51 & 32,9 & & 7,8 & & 19,7 & 52 & 47,3 & & 47,3 \\
\hline 18 & 50 & 3,16 & 4 & 2,4 & & 3,16 & & 2,9 & & 0,9 & & 0,6 & 4 & 2,8 & 11 & 4,5 & 1 & 0,6 & & 5,9 & & 2,6 & 17 & 15,5 & & 15,5 \\
\hline 26 & & 0,19 & & & & 1,9 & & 1,0 & & & & 0,2 & & & & & & & & & & 0,2 & & & & \\
\hline 31 & & 1,2 & 6 & 3,6 & & 9,49 & & 4,8 & & 0,9 & & 1,8 & 10 & 7,1 & 28 & 11,5 & 18 & 11,6 & & 56,9 & & 15,0 & 3 & 2,7 & & 2,7 \\
\hline 33 & & 4,55 & 2 & 1,2 & & 3,16 & & 3,0 & & & & 1,4 & 4 & 2,8 & 23 & 9,4 & 5 & 3,3 & & 2 & & 3,8 & 1 & 0,9 & & 0,9 \\
\hline 34 & & & & & & 1,9 & & 1,9 & & & & & & & & & & & & & & 0,0 & & & & \\
\hline 35 & & 0,44 & 2 & 1,2 & & 1,27 & & 1,0 & & 1,9 & & 0,6 & 4 & 2,8 & 8 & 3,3 & 2 & 1,2 & & 13,7 & & 3,9 & 0 & 0 & & 0 \\
\hline 39 & & 0,51 & & & & 17,09 & & 8,8 & & 1,5 & & 1,6 & 5 & 3,5 & 12 & 4,9 & 3 & 1,9 & & & & 2,7 & 2 & 1,8 & & 1,8 \\
\hline 45 & & 1,64 & & & & 1,27 & & 1,5 & & 0,2 & & 0,8 & 3 & 2,1 & 3 & 1,2 & & & & & & 1,1 & 0 & 0 & & 0 \\
\hline 51 & & 1,96 & 2 & 1,2 & & 7,59 & & 3,6 & & 10 & & 1,2 & 0 & 0 & 25 & 10,2 & 1 & 0,6 & & 7,8 & & 5,0 & 9 & 8,2 & & 8,2 \\
\hline 52 & & 1,27 & 4 & 2,4 & & 8,86 & & 4,2 & & 3,6 & & 1 & 17 & 12,1 & 17 & 7 & 5 & 3,3 & & 3,9 & & 5,2 & 1 & 0,9 & & 0,9 \\
\hline 53 & & 0,82 & 7 & 4,2 & & 6,33 & & 3,8 & & & & 1,2 & 1 & 0,7 & & & 1 & 0,6 & & 5,9 & & 2,1 & & & & \\
\hline 56 & & 2,15 & 2 & 1,2 & & 5,7 & & 3,0 & & 0,6 & & 1 & 1 & 0,7 & 14 & 5,7 & 1 & 0,6 & & 2 & & 1,8 & 5 & 4,6 & & 4,6 \\
\hline 58 & & 2,02 & 18 & 10,8 & & 10,76 & & 7,9 & & 1,3 & & 1,4 & 43 & 30,5 & 14 & 5,7 & 12 & 7,7 & & 43,1 & & 15,0 & 11 & 10 & & 10 \\
\hline 59 & & 0,82 & & & & 2,53 & & 1,7 & & 0,7 & & 2 & 3 & 2,1 & 4 & 1,6 & 1 & 0,6 & & 23,5 & & 5,1 & 9 & 8,2 & & 8,2 \\
\hline 66 & & 2,59 & 1 & 0,6 & & 8,86 & & 4,0 & & 5 & & 3,2 & 11 & 7,8 & 17 & 7 & 2 & 1,2 & & 29,4 & & 8,9 & & & & \\
\hline
\end{tabular}




\begin{tabular}{|c|c|c|c|c|c|c|c|c|c|c|c|c|c|c|c|c|c|}
\hline & \multicolumn{5}{|c|}{ REGIÓN COSTA } & \multicolumn{10}{|c|}{ REGIÓN SIERRA } & \multirow{2}{*}{\multicolumn{2}{|c|}{$\begin{array}{l}\text { OTROS } \\
\text { Dalgo P, } \\
2017\end{array}$}} \\
\hline & \multirow{2}{*}{$\begin{array}{c}\text { García G, } \\
2016 \\
3\end{array}$} & \multirow{2}{*}{\multicolumn{2}{|c|}{$\begin{array}{c}\text { Bedoya } \\
\text { C, } 2017 \\
6\end{array}$}} & \multirow{2}{*}{$\begin{array}{c}\text { García G, } \\
2019 \\
9\end{array}$} & \multirow[b]{2}{*}{ TOTAL } & \multirow{2}{*}{$\begin{array}{c}\text { Cárdenas } \\
0,2014 \\
1\end{array}$} & \multirow{2}{*}{$\begin{array}{c}\text { Cabrera } \\
\text { J, } 2015 \\
2\end{array}$} & \multicolumn{2}{|c|}{$\begin{array}{l}\text { Mejía L, } \\
2016\end{array}$} & \multicolumn{2}{|c|}{$\begin{array}{c}\text { Campoverde } \\
\text { A, } 2017\end{array}$} & \multicolumn{2}{|c|}{$\begin{array}{c}\text { Tigre P, } \\
2019\end{array}$} & \multirow{2}{*}{$\begin{array}{c}\text { Carrión } \\
\text { J, } 2020 \\
10\end{array}$} & & & \\
\hline & & & & & & & & & 4 & & & & & & TOTAL & 7 & TOTAL \\
\hline 67 & 0,38 & & & 0,63 & 0,5 & & & & & & & & & & 0,0 & & \\
\hline 68 & 0,19 & & & 5,06 & 2,6 & 1,3 & 2,8 & 5 & 3,5 & 4 & 1,6 & & & 7,8 & 3,4 & & \\
\hline 73 & 0,63 & 1 & 0,6 & 1,9 & 1,0 & & 0,4 & & & & & & & & 0,4 & & \\
\hline 82 & 0,38 & & & 1,9 & 1,1 & & 0,2 & & & & & & & 3,9 & 2,1 & & \\
\hline 85 & & & & & 0,0 & & & & & & & & & 2 & 2,0 & & \\
\hline BAJO RIESGO & & & & & 0,0 & & & & & & & & & & 0,0 & & \\
\hline 6 & 2,09 & 3 & 1,8 & 13,29 & 5,7 & 2,5 & 1 & 13 & 9,2 & & & & & 2 & 3,7 & & \\
\hline 11 & 3,8 & 1 & 0,6 & 5,06 & 3,2 & 2,5 & 0 & 13 & 9,2 & & & & & 2 & 3,4 & & \\
\hline 32 & & 1 & 0,6 & & 0,6 & & & & & & & & & & 0,0 & & \\
\hline 40 & 0,57 & & & 1,27 & 0,9 & & 0,4 & & & & & & & & 0,4 & & \\
\hline 42 & 0,76 & 1 & 0,6 & 3,16 & 1,5 & 4,7 & 2 & 1 & 0,7 & & & & & & 2,5 & & \\
\hline 43 & & & & 1,27 & 1,27 & 3,5 & 0,4 & 10 & 7,1 & & & & & & 3,7 & & \\
\hline 44 & & & & 1,9 & 1,9 & 1,2 & 0,6 & 1 & 0,7 & & & & & & 0,8 & & \\
\hline 49 & & & & & 0,0 & & & & & & & 3 & 1,9 & & 1,9 & & \\
\hline 54 & 2,09 & & & 5,7 & 3,9 & & 2 & & & & & & & 2 & 2,0 & & \\
\hline 55 & 0,82 & & & 1,9 & 1,4 & & & & & & & & & & 0,0 & & \\
\hline 57 & & & & 0 & 0,0 & & & & & & & & & & 0,0 & & \\
\hline 61 & 0,82 & 1 & 0,6 & 5,06 & 2,2 & & 1,6 & & & & & & & 37,3 & 19,5 & & \\
\hline 62 & 1,45 & 1 & 0,6 & & 1,0 & & & & & & & & & 3,9 & 3,9 & & \\
\hline 64 & 0,19 & & & & 0,19 & & & & & & & & & & 0,0 & & \\
\hline
\end{tabular}




\begin{tabular}{|c|c|c|c|c|c|c|c|c|c|c|c|c|c|c|c|c|}
\hline & \multicolumn{5}{|c|}{ REGIÓN COSTA } & \multicolumn{9}{|c|}{ REGIÓN SIERRA } & \multirow{2}{*}{\multicolumn{2}{|c|}{$\begin{array}{l}\text { OTROS } \\
\text { Dalgo P, } \\
2017\end{array}$}} \\
\hline & $\begin{array}{c}\text { García G, } \\
2016\end{array}$ & & $\begin{array}{l}\text { doya } \\
2017\end{array}$ & $\begin{array}{c}\text { García G, } \\
2019\end{array}$ & & $\begin{array}{l}\text { Cárdenas } \\
0,2014\end{array}$ & $\begin{array}{l}\text { Cabrera } \\
\text { J, } 2015\end{array}$ & & $\begin{array}{l}\text { ía } L, \\
16\end{array}$ & $\begin{array}{c}\text { Campoverde } \\
\text { A, } 2017\end{array}$ & & & $\begin{array}{l}\text { Carrión } \\
\text { J, } 2020\end{array}$ & & & \\
\hline & 3 & & 6 & 9 & TOTAL & 1 & 2 & & 4 & 5 & & & 10 & TOTAL & 7 & TOTAL \\
\hline 69 & 0,44 & & & 0,63 & 0,5 & & 0,2 & & & & & & & 0,2 & & \\
\hline 70 & 1,45 & 2 & 1,2 & 2,53 & 1,7 & & 0,4 & & & & & & 9,8 & 5,1 & & \\
\hline 71 & 0,82 & 1 & 0,6 & 3,16 & 1,5 & & 0,82 & & & & 3 & 1,9 & 2 & 1,6 & & \\
\hline 72 & 0,7 & 1 & 0,6 & 0 & 0,4 & & 0,7 & & & & & & 5,9 & 3,3 & & \\
\hline 81 & 0,63 & & & 9,49 & 5,1 & & 0,63 & 0 & 0 & & & & 9,8 & 3,5 & & \\
\hline 83 & 0,7 & & & 0,63 & 0,7 & & 0,7 & & & & & & 7,8 & 4,3 & & \\
\hline 84 & 1,2 & & & 0 & 0,6 & & 1,2 & & & & & & 5,9 & 3,6 & & \\
\hline CP6108 & 1,52 & & & & 1,52 & & 1,52 & & & & & & & 1,5 & & \\
\hline IS39 & 0,06 & & & & 0,06 & & 0,06 & & & & & & & 0,1 & & \\
\hline OTROS & & & & & 0,0 & & & & & & 15 & 9,6 & & 9,6 & & \\
\hline
\end{tabular}

La región Sierra tiene el doble de estudios publicados que la región Costa.

La prevalencia de los serotipos de VPH en la Costa en orden descendente fue la siguiente: $16,39,58,31,52,66,53,51,33,56,18,68,34,54,45,82,26,35,73$ y 67 para los serotipos de alto riesgo oncológico; para los de bajo riesgo oncológico son: 6, 81, 54, 11, 61, 44, 70, CP6108, 42, 71, 55, 43, 62, 40, 83, 32, 84, 69, 72, 64, IS39.

La prevalencia de los serotipos de VPH en la Sierra en orden descendente fue la siguiente: $16,31,58,66,52,59,51,35,33,68,39,18,53,82,85,56,45,73,26$ para los serotipos de alto riesgo oncológico; para los de bajo riesgo oncológico son: $61,70,83,62,6,43,84,81,11,72,42,54,49,71$, CP6108, 44, 40, 69 , IS39.

El estudio de Dalgo P, 2017 no pudo ser incluido con exactitud en ninguna de las regiones del Ecuador ya que se realizó de manera unificada en poblaciones pertenecientes a la Costa, Sierra y

Oriente. 
Tabla 5. Prevalencia de serotipos de VPH en relación con las Lesiones Intraepiteliales (LIE).

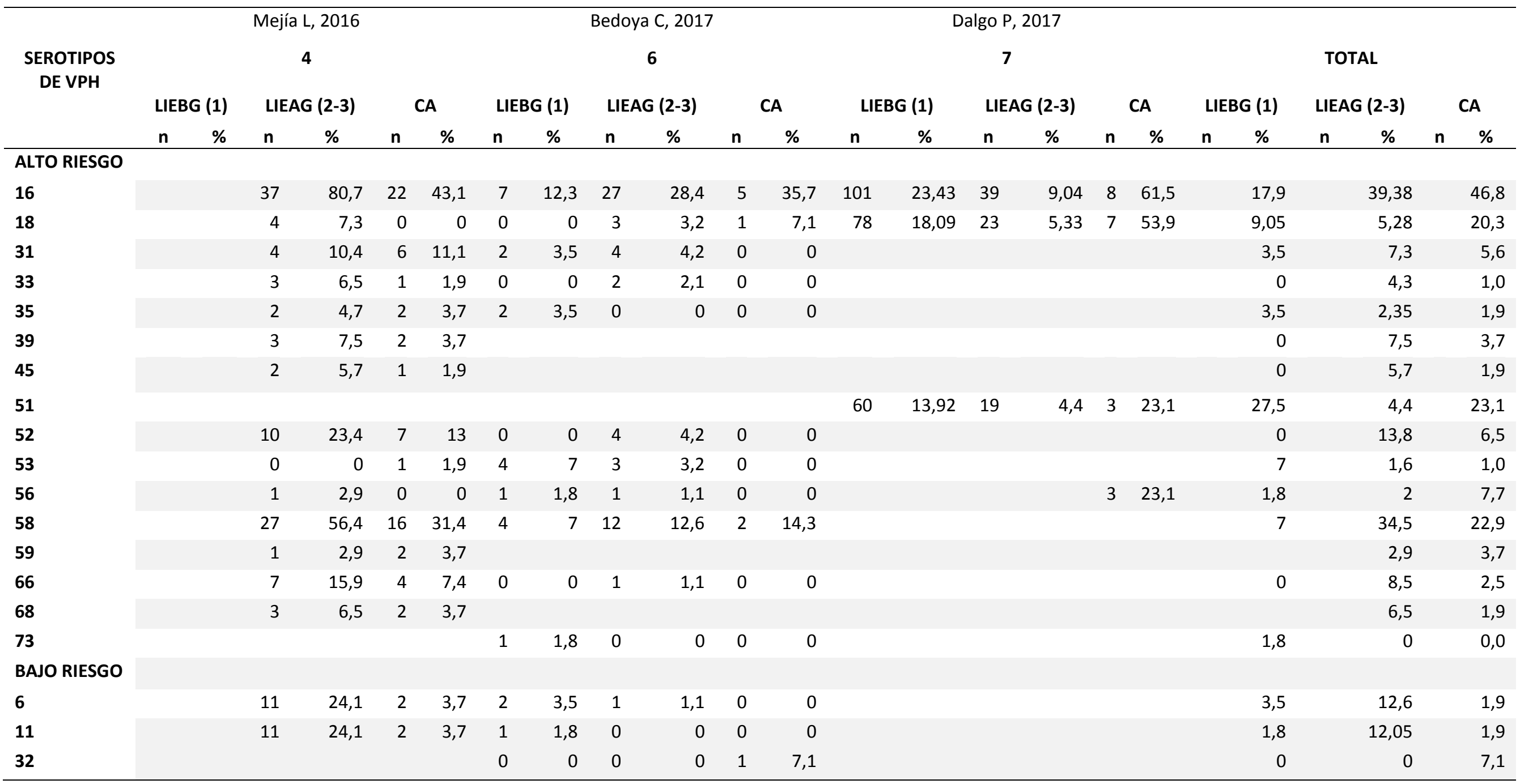




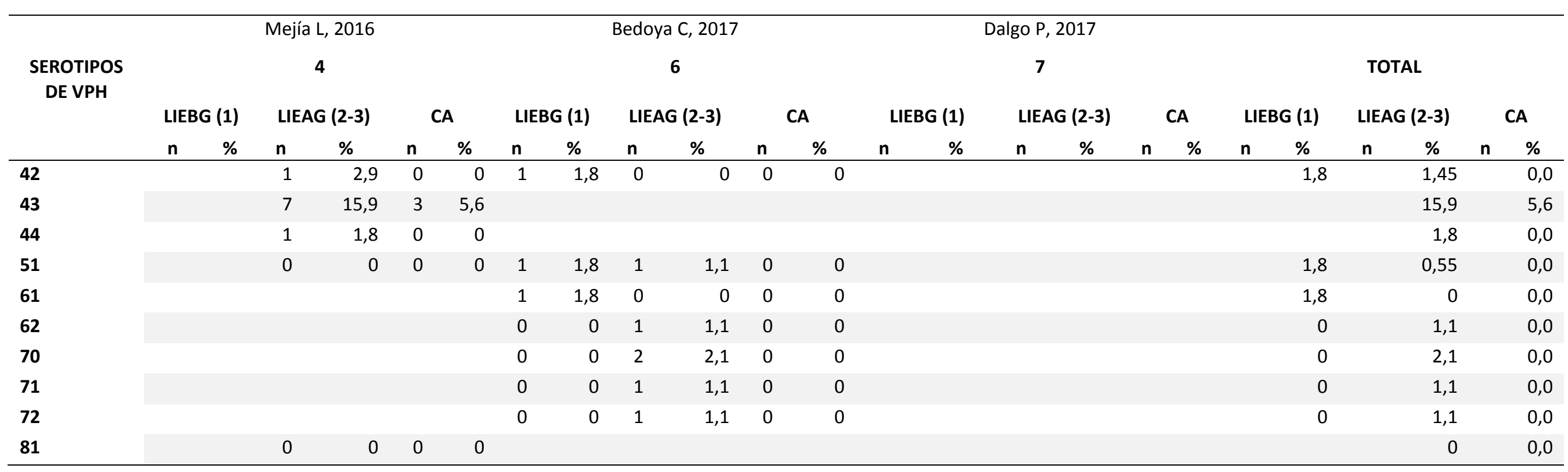

Únicamente tres estudios de todos los seleccionados para esta investigación reportan la prevalencia de serotipos de VPH en relación con el tipo de Lesión Intraepitelial (LIE).

En las LIE de bajo grado el orden descendente de la prevalencia de los serotipos de VPH fue: 51, 16, 18, 53, 31, 35, 56, 73 para el grupo de alto riesgo oncológico y el $6,11,42,51$ y 61 para los de bajo riesgo oncológico.

bajo riesgo oncológico.

$43,6,11,70,44,42,62,71,72$ y 51 para los de bajo riesgo oncológico.

En Cáncer el orden descendente de la prevalencia de los serotipos de VPH fue: 16, 51, 58, 18, 56, 52, 31, 39, 59, 66, 35, 45, 68, 33 y 53 para el grupo de alto riesgo oncológico y el $32,43,6$ y 11 para los de bajo riesgo oncológico. 
Tabla 6: Prevalencia de los serotipos de VPH en relación con la edad.

\begin{tabular}{|c|c|c|c|c|c|c|c|c|c|c|c|c|c|c|c|c|c|c|c|c|c|c|}
\hline \multirow{5}{*}{ SEROTIPOS DE VPH } & \multicolumn{8}{|c|}{ Cárdenas O, 2014} & \multicolumn{14}{|c|}{ Campoverde A, 2017} \\
\hline & \multicolumn{8}{|c|}{1} & \multicolumn{14}{|c|}{5} \\
\hline & \multicolumn{8}{|c|}{ GRUPOS DE EDAD } & \multicolumn{14}{|c|}{ GRUPOS DE EDAD } \\
\hline & \multicolumn{2}{|c|}{$17-19$} & \multicolumn{2}{|c|}{$20-29$} & \multicolumn{2}{|c|}{ 30-39 } & \multicolumn{2}{|c|}{$40-50$} & \multicolumn{2}{|c|}{$15-24$} & \multicolumn{2}{|c|}{$25-34$} & \multicolumn{2}{|c|}{$35-44$} & \multicolumn{2}{|c|}{ 45-54 } & \multicolumn{2}{|c|}{$55-64$} & \multicolumn{2}{|c|}{$65-74$} & \multicolumn{2}{|c|}{$>74$} \\
\hline & $\mathbf{n}$ & $\%$ & $\mathbf{n}$ & $\%$ & $\mathbf{n}$ & $\%$ & $\mathbf{n}$ & $\%$ & $\mathbf{n}$ & $\%$ & $\mathbf{n}$ & $\%$ & $\mathbf{n}$ & $\%$ & $\mathbf{n}$ & $\%$ & $\mathbf{n}$ & $\%$ & $\mathbf{n}$ & $\%$ & $\mathbf{n}$ & $\%$ \\
\hline VPH POSITIVO & & & & & & & & & 70 & 17,9 & 187 & 47,7 & 82 & 20,9 & 38 & 9,7 & 11 & 2,8 & 3 & 0,8 & 1 & 0,3 \\
\hline VPH NEGATIVO & & & & & & & & & 12 & 11,1 & 42 & 38,9 & 38 & 35,2 & 16 & 14,8 & 0 & 0 & 0 & 0 & 0 & 0 \\
\hline \multicolumn{23}{|l|}{ ALTO RIESGO } \\
\hline 16 & & & & & & & & & 13 & 20,3 & 29 & 45,3 & 12 & 18,8 & 7 & 10,9 & 2 & 3,1 & 0 & 0 & 1 & 1,6 \\
\hline 18 & 0 & 0 & 2 & 40 & 1 & 20 & 2 & 40 & 3 & 27,3 & 7 & 63,6 & 0 & 0 & 1 & 9,1 & 0 & 0 & 0 & 0 & 0 & 0 \\
\hline 31 & 0 & 0 & 2 & 40 & 1 & 20 & 2 & 40 & 4 & 14,3 & 16 & 57,1 & 4 & 14,3 & 2 & 7,1 & 2 & 7,1 & 0 & 0 & 0 & 0 \\
\hline 33 & 0 & 0 & 1 & 33,3 & 1 & 33,3 & 1 & 33,3 & 4 & 17,4 & 13 & 56,5 & 6 & 26,1 & 0 & 0 & 0 & 0 & 0 & 0 & 0 & 0 \\
\hline 35 & 0 & 0 & 4 & 40 & 2 & 20 & 4 & 40 & 2 & 25 & 3 & 37,5 & 2 & 25 & 1 & 12,5 & 0 & 0 & 0 & 0 & 0 & 0 \\
\hline 39 & & & & & & & & & 1 & 8,3 & 7 & 58,3 & 3 & 25 & 1 & 8,3 & 0 & 0 & 0 & 0 & 0 & 0 \\
\hline 45 & & & & & & & & & 1 & 33,3 & 2 & 66,7 & 0 & 0 & 0 & 0 & 0 & 0 & 0 & 0 & 0 & 0 \\
\hline 51 & 0 & 0 & 19 & 34,5 & 22 & 40 & 14 & 25,5 & 5 & 20 & 10 & 40 & 6 & 24 & 1 & 4 & 2 & 8 & 1 & 4 & 0 & 0 \\
\hline 52 & & & & & & & & & 1 & 5,9 & 8 & 47,1 & 5 & 29,4 & 3 & 17,6 & 0 & 0 & 0 & 0 & 0 & 0 \\
\hline 56 & 0 & 0 & 2 & 66,7 & 1 & 33,3 & 0 & 0 & 4 & 28,6 & 4 & 28,6 & 5 & 35,7 & 1 & 7,1 & 0 & 0 & 0 & 0 & 0 & 0 \\
\hline
\end{tabular}




\begin{tabular}{|c|c|c|c|c|c|c|c|c|c|c|c|c|c|c|c|c|c|c|c|c|c|c|}
\hline \multirow{5}{*}{ SEROTIPOS DE VPH } & \multicolumn{8}{|c|}{ Cárdenas O, 2014} & \multicolumn{14}{|c|}{ Campoverde A, 2017} \\
\hline & \multicolumn{8}{|c|}{1} & \multicolumn{14}{|c|}{5} \\
\hline & \multicolumn{8}{|c|}{ GRUPOS DE EDAD } & \multicolumn{14}{|c|}{ GRUPOS DE EDAD } \\
\hline & \multicolumn{2}{|c|}{$17-19$} & \multicolumn{2}{|c|}{$20-29$} & \multicolumn{2}{|c|}{$30-39$} & \multicolumn{2}{|c|}{$40-50$} & \multicolumn{2}{|c|}{$15-24$} & \multicolumn{2}{|c|}{$25-34$} & \multicolumn{2}{|c|}{$35-44$} & \multicolumn{2}{|c|}{$45-54$} & \multicolumn{2}{|c|}{$55-64$} & \multicolumn{2}{|c|}{$65-74$} & \multicolumn{2}{|c|}{$>74$} \\
\hline & $\mathbf{n}$ & $\%$ & $\mathbf{n}$ & $\%$ & $\mathbf{n}$ & $\%$ & $\mathbf{n}$ & $\%$ & $\mathrm{n}$ & $\%$ & $\mathbf{n}$ & $\%$ & $\mathrm{n}$ & $\%$ & $\mathbf{n}$ & $\%$ & $\mathbf{n}$ & $\%$ & $\mathbf{n}$ & $\%$ & $\mathbf{n}$ & $\%$ \\
\hline 58 & & & & & & & & & 1 & 7,1 & 6 & 42,9 & 4 & 28,6 & 3 & 21,4 & 0 & 0 & 0 & 0 & 0 & 0 \\
\hline 59 & & & & & & & & & 0 & 0 & 4 & 100 & 0 & 0 & 0 & 0 & 0 & 0 & 0 & 0 & 0 & 0 \\
\hline 66 & & & & & & & & & 3 & 17,6 & 10 & 58,8 & 3 & 17,6 & 1 & 5,9 & 0 & 0 & 0 & 0 & 0 & 0 \\
\hline 68 & & & & & & & & & 0 & 0 & 1 & 25 & 1 & 25 & 1 & 25 & 1 & 25 & 0 & 0 & 0 & 0 \\
\hline \multicolumn{23}{|l|}{ BAJO RIESGO } \\
\hline 6 & 0 & 0 & 3 & 23,1 & 2 & 15,4 & 8 & 61,5 & & & & & & & & & & & & & & \\
\hline 11 & 0 & 0 & 3 & 23,1 & 2 & 15,4 & 8 & 61,5 & & & & & & & & & & & & & & \\
\hline 44 & 0 & 0 & 1 & 16,7 & 4 & 66,7 & 1 & 16,7 & & & & & & & & & & & & & & \\
\hline
\end{tabular}

Únicamente dos estudios relacionaron la prevalencia de los serotipos de VPH con la edad de las mujeres que participaron en los estudios.

En un estudio realizado en el 2014 el serotipo de alto riesgo oncológico que mayor prevalencia presentó fue el 56 en mujeres entre 20 y 29 años y el de bajo riesgo oncológico fue el serotipo 44 en el rango de edad entre 30 y 39 años.

En otro estudio realizado en el 2017 la mayor parte de los serotipos de alto riesgo oncológico presentaron una prevalencia alta en mujeres con edades comprendidas entre 25 y 34 años. 
Gráfico 1. Tendencia de la prevalencia de serotipos de VPH en las mujeres de Ecuador

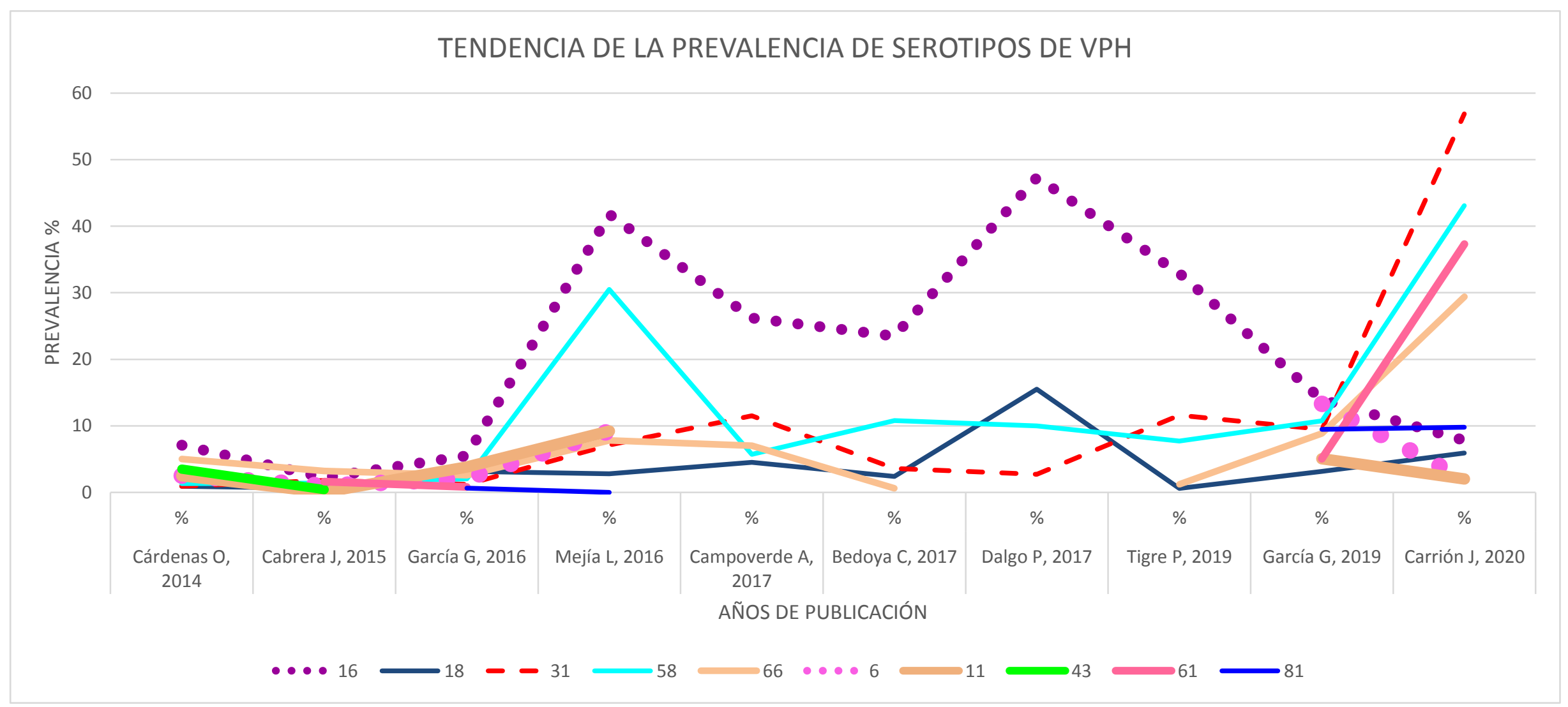


En el transcurso de los años se ha podido observar ascensos y descensos de la prevalencia de los serotipos de VPH en las mujeres ecuatorianas. Algunos de los serotipos de alto riesgo oncológico alcanzaron su pico máximo entre los años 2016 - 2019. En el último año se ha presentado un ascenso considerativo del serotipo 31 el cual alcanzó una prevalencia superior al 50\%. Otros serotipos cuya prevalencia aumentó en el último año fueron el 18, 58 y 66; por otra parte, se observó un descenso del serotipo 16. En cuanto a los serotipos de bajo riesgo oncológico, el serotipo 81 presentó una tendencia de ascenso, el serotipo 61 es el que tiene un mayor aumento en su prevalencia. Los serotipos 6 y 11 presentaron un ascenso en el año 2019 y un descenso en el año 2020; y el serotipo que ha presentado una tendencia de descenso es el 43

\section{DISCUSIÓN}

C on esta investigación se pudo evidenciar que no es posible establecer una prevalencia de serotipos de VPH global del todo clara debido a las diferencias en las variables de estudio, población, muestra, muestreo, tipo de diagnóstico, rango de edad, zona geográfica ya que existen varias zonas del Ecuador que no cuentan con los estudios suficientemente confiables como para ser considerados en este tipo de investigaciones.

Muchos estudios reportan que los serotipos de alto riesgo oncológico más prevalentes son el 16 y 18, responsables del 70\% de los cánceres de cuello uterino (26). Mientras que los de bajo riesgo oncológico son los serotipos 6 y 11 (27), lo cual difiere de esta investigación debido a que el serotipo 18 no es de los más prevalentes. Por el contrario, en su lugar se encuentra el serotipo 58, mostrando gran similitud con un estudio realizado en Argentina. En donde los más prevalentes fueron 16, 58, 53, 31, 6 y 18 (28); esto debido a las diferencias existentes entre la población de América Latina, donde el estudio determina que los más comunes son 33,39 y 59, mientras que el serotipo 18 es más prevalente en países como Indonesia y Argelia (29).

Las zonas de la Costa y de la Sierra no presentan similitudes entre los serotipos de VPH a excepción del 16 y 58 presente en estas zonas geográficas. Estas diferencias podrían deberse a las prácticas sexuales de la población, la edad de inicio de vida sexual y la multiparidad en cada una de las zonas. Ya que estudios demuestran que en la sierra ecuatoriana el inicio de la actividad sexual se da entre los 15 y 19 años, y más del 50\% de la población tienen entre 1 a 3 parejas sexuales durante toda su vida. Mientras que en la costa el inicio de actividad sexual es de 14 a 17 años y el alto consumo de alcohol se correlaciona con el número de parejas sexuales y practicas inusuales $(30,31)$.

Relacionando los serotipos con el tipo de LIE que presentaban la población de estudio se observó que el serotipo más frecuente para aquellas mujeres que presentaban un LIE de bajo riesgo fue el 51 seguido de los serotipos 16 y 18 correspondientes a serotipos de alto riesgo oncológico y dentro de los de bajo riesgo oncológico están los serotipos 6 y 11. En relación con la LIE de alto riesgo los más frecuente fueron el 16, 58 y 52, dentro de los serotipos de bajo riesgo están el 43, 6 y 11. En aquellas mujeres que presentaban un diagnóstico de cáncer la prevalencia del serotipo 16 fue el doble en comparación con los otros serotipos frecuentes como lo 
son el 51, 58 y 18, dentro de los serotipos de bajo riesgo oncológico se encontraron el 32 seguido del 43. Estos datos difieren de un estudio realizado en Colombia en donde en las LIE de bajo riesgo los serotipos más prevalentes fueron para: 16 , $58,56,18,31$ y 51 del grupo de alto riesgo oncológico; los de bajo riesgo oncológico fueron: 66, 53, 70 y 34. Para las LIE de alto riesgo los más prevalentes fueron:16, 58, 18,31 y 56 correspondientes a los serotipos de alto riesgo oncológico, y los de bajo riesgo oncológico: 70, 66, 68 y 53; observándose que solo los serotipos 16 y 58 son prevalentes en ambos países (32).

Únicamente tres estudios relacionaron el tipo de LIE con los serotipos de VPH lo cual fue un limitante ya que no es posible conocer con precisión la verdadera prevalencia de los serotipos causantes de las diferentes lesiones. Por lo que sería recomendable que las investigaciones que estudian las prevalencias de los serotipos de VPH evalúen también el tipo de LIE para así conocer con exactitud que serotipo es responsable de cada una de las alteraciones morfológicas de las células del cuello uterino.

Los dos estudios en donde se relacionaron la prevalencia de los serotipos de VPH con la edad de las participantes mostraron que la mayoría de los serotipos de alto riesgo oncológico se encontraron en aquellas mujeres que tenían edades de 20 a 34 años. Diversos estudios indican que la edad es un factor de riesgo para adquirir una infección, siendo estas más comunes en mujeres jóvenes que son sexualmente más activas. Esto según un metaanálisis realizado en los 5 continentes en donde se determinó que las mujeres de más 25 años presentaban una alta prevalencia de VPH, misma que disminuía gradualmente después de los 35 años y volvía a incrementarse a partir de los 45 años en América Latina y más de 55 años en África Occidental $(27,33)$.

Igualmente se ha podido constatar que las diferentes vacunas que están disponibles en el mercado como lo son la bivalente, la tetravalente y la nonavalente pueden resultar efectivas en una parte de la población ecuatoriana. Sin embargo, solamente ofrecen protección contra 9 de los 43 serotipos de VPH circulantes en el Ecuador; pero ninguna de estas vacunas provoca inmunidad contra otros serotipos prevalentes en el país como lo son 61,66 , 81, 51, 59 y 39. El Ministerio de Salud Pública aplicó la vacuna bivalente en el año 2014 dirigida únicamente a los serotipos 16 y 18 de manera gratuita a las niñas de 9 a 12 años a través del Programa Ampliado de Inmunizaciones (PAI). Pero como se pude evidenciar la cantidad de serotipos circulantes en el país es mayor y existen otros serotipos que no están incluidos en esta vacuna por lo que la protección que ofrece la misma es mínima. Por lo tanto, el gobierno a través de las entidades de salud debería considerar estos resultados y mejorar las medidas de prevención de las infecciones causadas por el VPH. Las cuales son causantes del cáncer cérvico uterino que es la segunda causa de muerte en el país.

\section{CONCLUSIÓN}

$\mathrm{N}$ o todas las regiones de Ecuador cuentan con estudios relacionadas a la problemática como lo son la región Amazónica y la región Insular por lo que no se pudo determinar la prevalencia de serotipos de VPH en estas zonas. Sin embargo, las otras regiones si presentaron datos mostrando que lo serotipos de alto riesgo oncológico más frecuentes en las mujeres del Ecuador 
son 16, 58 y 31 , mientras que los de bajo riesgo oncológico son 61, 81 y 6 .

Los laboratorios clínicos que realizan la genotipificación de VPH deben tener en cuenta los serotipos circulantes en Ecuador. Ya que la mayoría de las pruebas comerciales están dirigidas a la identificación de los serotipos 16, 18, 6, 11 $\mathrm{y}$ no incluyen a todos los serotipos encontrados en esta investigación. Por lo cual, no se tendría un diagnóstico preciso y las infecciones causadas por otros serotipos pasarían desapercibidas y generarían un mayor problema de salud.

\section{REFERENCIAS BIBLIOGRÁFICAS}

1. Domínguez S, Trujillo $\mathrm{T}$, Aguilar $\mathrm{K}$, Hernández M. Infección por el virus del papiloma humano en adolescentes y adultas jóvenes. Revista Cubana de Obstetricia y Ginecología [Internet]. 2018 [citado 2 de agosto de 2020];44(1):1-13. Disponible en: http://scielo.sld.cu/

scielo.php?script=sci_abstract\&pid=S0138-

600X2018000100017\&lng=es\&nrm=iso\&tln $\mathrm{g}=\mathrm{es}$

2. Rodas E, Pazmiño B, Coello R, Bermudez J, Rodas KR, Cagua L, et al. Detección serológica del Virus Papiloma Humano en mujeres mayores de 20 años. Caso sector "Gary Esparza", Babahoyo, Ecuador // Serological detection of human papilloma virus in women over 20 years. "Gary Esparza" sector, Babahoyo, Ecuador. CIENCIA UNEMI [Internet]. 2017 [citado 21 de abril de 2020];10(23):112-5. Disponible en: $\quad$ http://ojs.unemi.edu.ec/ index.php/cienciaunemi/article/view/503

3. Naranjo I, Cuzco A, Cuzco L. Eficacia de la vacuna nonavalente en la prevención de la infección por Virus Papiloma Humano (HPV) y cáncer cervical. CSSN [Internet]. 2018 [citado 23 de abril de 2020];9(2):30-7. Disponible

en: http://revistas.espoch.edu.ec/index.php/css n/article/view/88
4. Li Y, Xu C. Human Papillomavirus-Related Cancers. Adv Exp Med Biol [Internet]. 2017;1018:23-34. Disponible en: https://pubmed.ncbi.nlm.nih.gov/29052130 /

5. St. Laurent J, Luckett R, Feldman S. HPV vaccination and the effects on rates of HPVrelated cancers. Current Problems in Cancer [Internet]. 2018 [citado 11 de marzo de 2021];42(5):493-506. Disponible en: https://www.sciencedirect.com/science/art icle/pii/S0147027218301351

6. World Health Organization. Electronic address: sageexecsec@who.int. Human papillomavirus vaccines: WHO position paper, May 2017. Vaccine [Internet]. 2017;92(19):241-68. Disponible en: https://pubmed.ncbi.nlm.nih.gov/28596091 /

7. Tumban E. A Current Update on Human Papillomavirus-Associated Head and Neck Cancers. Viruses [Internet]. 2019 [citado 20 de diciembre de 2020];11(10):9-22. Disponible en: https://www.ncbi.nlm. nih.gov/pmc/articles/PMC6833051/

8. Balasubramaniam $S$, Balakrishnan $V$, Oon C, Kaur G. Key Molecular Events in Cervical Cancer Development. Medicina (Kaunas) [Internet]. 2019 [citado 20 de diciembre de 2020];55(7):384. Disponible en: https://www.ncbi.nlm.nih.gov/pmc/articles /PMC6681523/

9. Zhang L, Bi Q, Deng H, Xu J, Chen J, Zhang $M$, et al. Human papillomavirus infections among women with cervical lesions and cervical cancer in Eastern China: genotypespecific prevalence and attribution. BMC Infect Dis [Internet]. 2017 [citado 20 de diciembre de 2020];17(1):107. Disponible en:

https://www.ncbi.nlm.nih.gov/pmc/articles /PMC5282745/

10. Instituto nacional de estadística y censos. Población y Demografía [Internet]. Instituto Nacional de Estadística y Censos. [citado 10 de mayo de 2021]. Disponible en:

https://www.ecuadorencifras.gob.ec/cens o-de-poblacion-y-vivienda/ 
11. Zelada A, Fando R. La pandemia subvalorada del siglo XXI: el virus del papiloma humano. Su repercusión en la patogenia del cáncer cervicouterino. Revista CENIC Ciencias Biológicas [Internet]. 2013 [citado 16 de mayo de 2020];44(2):1-21. Disponible en: https://www.redalyc.org/articulo.oa?id=1 81227534004

12. Bharti A, Singh T, Bhat A, Pande D, Jadli M. Therapeutic startegies for human papillomavirus infection and associated cancers. Front Biosci (Elite Ed) [Internet]. 2018;10:15-73. Disponible en: https://pubmed.ncbi.nlm.nih.gov/289306 04/

13. Moya J, Rojas V. Tendencias en la investigación del virus de papiloma humano en Latinoamérica frente a los países de altos ingresos. Rev Colomb Obstet Ginecol [Internet]. 2017 [citado 2 de agosto de 2020];68(3):202-17. Disponible en: http://www.scielo.org.co/scielo.php?scrip $\mathrm{t}=$ sci_abstract $\&$ pid=S0034-

$74342017000300202 \& \operatorname{lng}=$ en $\& \mathrm{nrm}=\mathrm{i}$ so \&t lng=es

14. Cabrera J, Cárdena 0 , Campoverde $M$, Ortiz J. Prevalencia de genotipos del papiloma virus humano en mujeres de la provincia del Azuay, Ecuador. Maskana [Internet]. 2015 [citado 21 de abril de 2020];6(1):79-93. Disponible en: https://publicaciones.ucuenca.edu.ec/ojs/ index.php/maskana/article/view/477

15. Manini I, Montomoli E. Epidemiology and prevention of Human Papillomavirus. Ann Ig [Internet]. 2018;30(4):28-32. Disponible en: https://pubmed.ncbi.nlm.nih.gov/300623 77 /

16. Zapata S, Mosquera J, Mejía L, Cruz L, Sánchez S, García M, et al. Estudios sobre el virus del papiloma humano y cáncer cervical en el Ecuador. INSPILIP [Internet]. 2019 [citado 6 de mayo de 2020];3(1):115. Disponible en: https://www.inspilip. gob.ec/OJS/index.php/inspilip/article/vie $\mathrm{w} / 73$
17. Cárdenas O, Cabrera J, Campoverde A. Prevalencia de genotipos del Papiloma virus en mujeres de Cuenca. Rev Fac Cienc Méd Univ Cuenca [Internet]. 2014 [citado 19. de enero de 2021];32(1):6-15. Disponible en: https://publicaciones.ucuenca.edu.ec/ojs/ index.php/medicina/article/view/874/77 4

18. García G, García L, Burgos R, Almeida F, Ruiz J. Genotypes distribution of human papillomavirus in cervical samples of Ecuadorian women. Rev Bras Epidemiol [Internet]. 2016;19(1):160-6. Disponible en:

http://www.scielo.br/scielo.php?script=sc i_arttext\&pid=S1415-

790X2016000100160

19. Mejía L, Muñoz D, Trueba G, Tinoco L, Zapata S. Prevalence of human papillomavirus types in cervical cancerous and precancerous lesions of Ecuadorian women. J Med Virol [Internet]. 2016;88(1):144-52. Disponible en: https://pubmed.ncbi.nlm.nih.gov/261134 43/

20. Campoverde A, Arcentales M, Caguana J. Caracterización de los genotipos frecuentes del Virus del Papiloma Humano en mujeres atendidas en los Hospitales Monte Sinaí y del Seguro Social CuencaEcuador. 2008- 2014. Rev Fac Cienc Méd Uni Cuenca [Internet]. 2017 [citado 22 de abril de 2020];35(1):7-19. Disponible en: https://publicaciones.ucuenca.edu.ec/ojs/ index.php/medicina/article/view/2765

21. Bedoya $C$, Medina L, Espinosa $M$, Sánchez M, Parrales J, Molina D, et al. Molecular epidemiology and phylogenetic analysis of human papillomavirus infection in women with cervical lesions and cancer from the coastal region of Ecuador. Rev Argent Microbiol [Internet]. 2018;50(2):136-46. Disponible en: https://www.sciencedirect.com/science/a rticle/pii/S0325754117301372

22. Dalgo P, Loján C, Córdova A, Acurio K, Arévalo A, Bobokova J. Prevalence of HighRisk Genotypes of Human Papillomavirus: 
Women Diagnosed with Premalignant and Malignant Pap Smear Tests in Southern Ecuador. Infect Dis Obstet Gynecol [Internet]. 2017;20(17):1-7. Disponible en: https://www.hindawi.com/journals/idog/ 2017/8572065/

23. Tigre P, Salazar Z, Espinosa L, Aspiazu $\mathrm{K}$, Espinosa $\mathrm{H}$, Cárdena $\mathrm{F}$. Human Papilloma Virus genotypes in Type III cervical intraepithelial neoplasia. Cuenca-Ecuador, 2013-2017. Kasmera [Internet]. 2019 [citado 22 de abril de 2020];47(2):95-101. Disponible en: http://produccioncientificaluz.org/index.p hp/kasmera/article/view/25234/html

24. García G, Mendoza M, Burgos RI, Ollague K, Vargas C, Ruiz J. Frequency and distribution of HPV genotypes in 800 genital samples of Ecuadorian men and women from the city of Guayaquil. Rev Inst Med Trop Sao Paulo [Internet]. 2019 [citado 5 de mayo de 2020];61(41):1-5. Disponible en: http://www.scielo.br/ scielo.php?script=sci_abstract\&pid=S0036$46652019005000606 \& \operatorname{lng}=\mathrm{en} \& \mathrm{nrm}=\mathrm{iso} \& \mathrm{t}$ lng=en

25. Carrión J, Soto Y, Pupo M. Infección por virus del papiloma humano en mujeres del Cantón Cañar, Ecuador. Rev Cubana Med Trop [Internet]. 2020 [citado 2 de agosto de 2020];72(1):1-20. Disponible en: http://scielo.sld.cu/scielo.php?script=sci_a bstract\&pid=S0375-

07602020000100006\&lng=es\&nrm=iso\&t lng=es

26. World Health Organization. Papilomavirus humanos (PVH) y cáncer cervicouterino [Internet]. Human Papillomavirus and cervical cancer. 2020 [citado 13 de marzo de 2021]. Disponible en: $\quad$ https://www.who.int/es/newsroom/fact-sheets/detail/humanpapillomavirus-(hpv)-and-cervical-cancer

27. Bruni L, Diaz M, Castellsagué M, Ferrer E, Bosch X, de Sanjosé S. Cervical Human Papillomavirus Prevalence in 5 Continents: Meta-Analysis of 1 Million Women with Normal Cytological Findings. The Journal of Infectious Diseases [Internet]. 2010 [citado 13 de marzo de
2021];202(12):1789-99. Disponible en: https://doi.org/10.1086/657321

28. Marín H, Torres C, Deluca G, Mbayed V. Human papillomavirus detection in Corrientes, Argentina: High prevalence of type 58 and its phylodynamics. Rev Argent Microbiol [Internet]. 2015 [citado 13 de marzo de 2021];47(4):302-11. Disponible en:

https://www.sciencedirect.com/science/a rticle/pii/S0325754115001194

29. Rivera R, Aguilera J, Larraín A. Epidemiología del Virus Papiloma Humano (HPV). Rev Chil Obstet Ginecol [Internet]. 2002 [citado 13 de marzo de 2021];67(6):501-6. Disponible en: https://scielo.conicyt.cl/scielo.php?script= sci_abstract\&pid=S0717-

$75262002000600013 \& \operatorname{lng}=e s \& n r m=i s o \& t$ lng=es

30. Saeteros R, Pérez J, Sanabria G. Conducta de riesgo y problemas sexuales y reproductivos de estudiantes universitarios ecuatorianos. Rev Hum Med [Internet]. 2015 [citado 13 de marzo de 2021];15(3):421-39. Disponible en: http://www.humanidadesmedicas.sld.cu/i ndex.php/hm/article/view/760

31. Robles J, Espinel J. Riesgo Sexual Y Nivel De Popularidad En Estudiantes Universitarios Del Ecuador. Interam J Psychol [Internet]. 2017 [citado 13 de marzo de 2021];51(2):152-61. Disponible en:

https://www.redalyc.org/articulo.oa?id=2 8454546002

32. Trujillo E, Morales N, Buitrago O, Posso $\mathrm{H}$, Bravo M. Distribución de los genotipos del virus del papiloma humano en mujeres de Bogotá con anomalías en la citología cervicouterina. Rev Colomb Cancerol [Internet]. 2016 [citado 13 de marzo de 2021];20(1):3-9. Disponible en: http://www.elsevier.es/es-revista-revistacolombiana-cancerologia-361-articulodistribucion-genotipos-del-virus-delS0123901515000955 
33. Sanoja L. Detección y tipificación del virus del papiloma humano mediante reacción en cadena de polimerasa, en muestras cervicales de estudiantes: Universidad de Carabobo. Venezuela. Comunidad y Salud [Internet]. 2013 [citado 13 de marzo de 2021];11(2):1-10. Disponible en: http://ve.scielo.org/scielo. php?script
=sci_abstract\&pid=S1690-32932013000200 002\&lng=es\&nrm=iso\&tlng=es

Conflicto de interese: Los autores declaran que no existe conflicto de intereses para la publicación del presente artículo.

Financiamiento: Autofinanciamiento

Agradecimiento: No declaran 